\title{
CRESCIMENTO E CONCENTRAÇÃO DE HEMOGLOBINA DE LACTENTES EM ALEITAMENTO MATERNO EXCLUSIVO
}

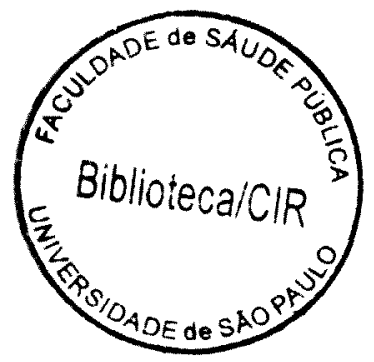

SANDRA PINHEIRO CHAVES

Tese apresentada ao Departamento de Nutrição da Faculdade de Saúde Pública da Universidade de São Paulo para obtenção do Título de Doutor em Saúde Pública.

Área de concentração: Nutrição

Orientador: PROF.DR. SOPHIA CORNBLUTH SZARFARC 
Autorizo, exclusivamente para fins acadêmicos e científicos, a reprodução total ou parcial desta tese, por processos fotocopia dores.

Assinatura: Exuratitibuktures

Data: $24103 / 99$

$$
38590199 \text { dec }
$$




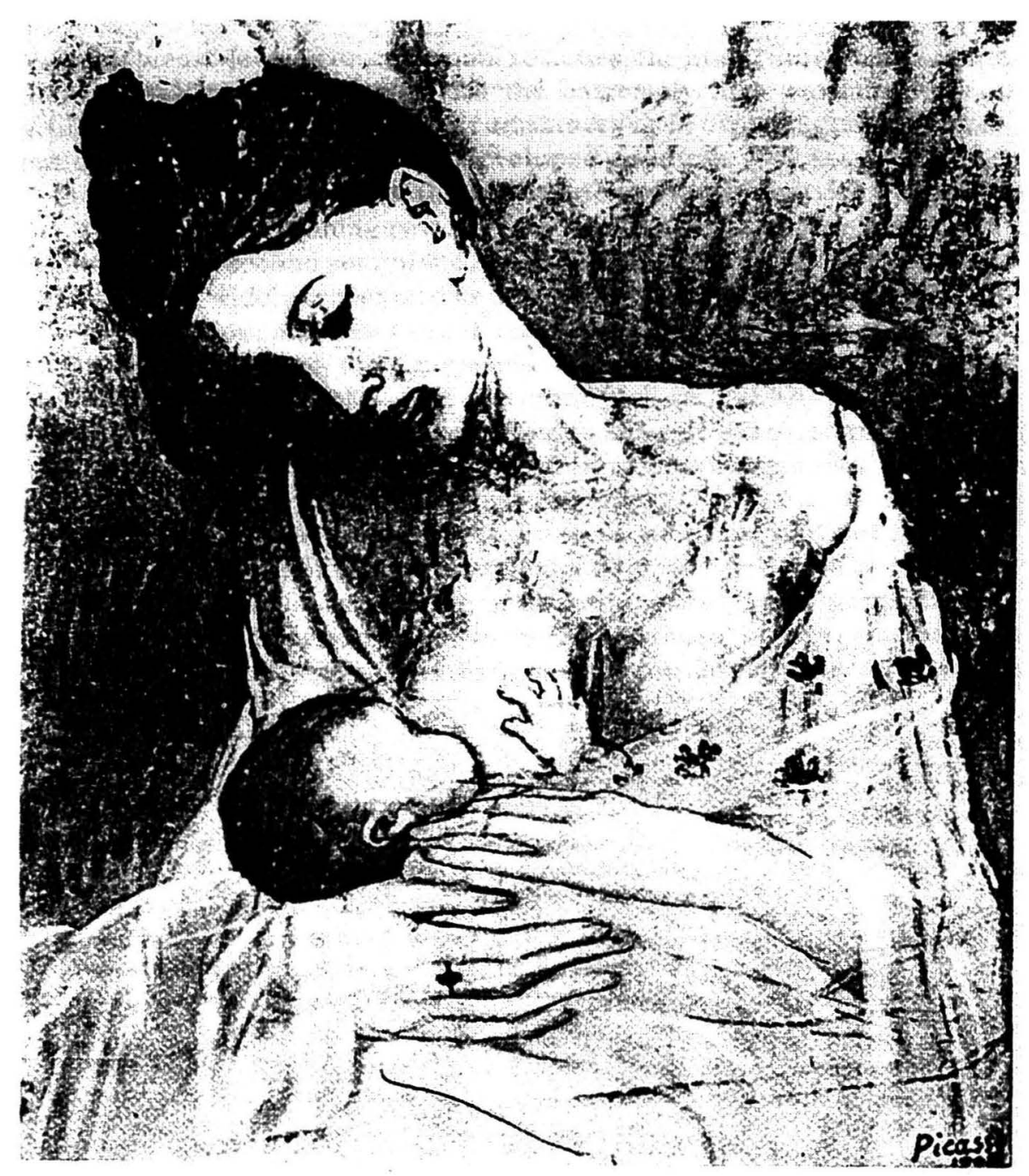

'Maternity' by Pablo Picasso (1905). Mother and baby in eye-to-eye contact, almost 'en face' @ $\odot$ by S.P.D.E.M., Paris 1977 
"A criança é a única matéria conhecida com a qual o homem pode ser feito".

Policlínica de Saúde de Santos. 
Aos meus pais

Livio e Célia

pelo carinho e apoio que sempre me dedicaram. 
Ao Gianni

companheiro e amigo

e aos meus filhos

Mario e Fernanda

pelo amor e compreensão. 
À Aldonia Cekaunaskas Kalil (in memorian)

Pelo exemplo profissional, amizade e apoio. 


\section{AGRADECIMENTOS}

À Professora Doutora Sophia Cornbluth Szarfarc, pelo apoio, carinho e dedicação acrescentados à sua orientação segura e competente.

À Dra. Keiko Teruya do Centro de Lactação de Santos sempre presente para solucionar os problemas durante a fase de campo deste trabalho.

À Dra. Olímpia M.N. Peel de Oliveira, responsável pela colheita e preparação do sangue para as dosagens bioquímicas

Às nutricionistas e pesquisadoras Barbara Regina Lerner, Doris Lúcia Martini Lei, Maria Lúcia Rosa Stefanini, Marly Augusto Cardoso e Lenise Mondini pela amizade, apoio e discussão durante o desenvolvimento deste trabalho.

À Tereza Etsuko Rosa pela valiosa contribuição e pela realização das análises estatísticas.

À Eliete Cândida de Lima Cortez, Diretora do Núcleo de Informática do Instituto de Saúde pelo carinho e apoio.

Ao Professor José Maria Pacheco pelas sugestões.

À Rosita José da Silva, Técnica de Apoio à Pesquisa Científica do Instituto de Saúde responsável pela digitação e editoração deste trabalho.

À Aparecida Natália Rodrigues, Técnica de Apoio à Pesquisa Científica do Instituto de Saúde pela amizade e ajuda oportuna.

A Simone Ribeiro Spinetti, aprimoranda da FUNDAP, responsável pela montagem do banco de dados. 
Aos colegas do Núcleo de Informática do Instituto de Saúde pela ajuda.

À Carmem Campos Arias Paulenas e Maria Aparecida Esteves, bibliotecárias do Instituto de Saúde pela localização de várias referências bibliográficas.

Á Professora e amiga Leila Anção Saul pela revisão de português.

À bibliotecária da Faculdade de Saúde Pública Maria Lúcia de Faria Ferraz pela revisão bibliográfica.

À Fundação de Amparo à Pesquisa do Estado de São Paulo (FAPESP) pelo auxilio financeiro através do processo $n^{\circ} 94.4431-3$.

À toda equipe do Centro de Lactação de Santos.

Às mães e crianças do Centro de Lactação de Santos sem as quais este trabalho não poderia ser realizado. 


\section{Resumo}

Objetivo: É reconhecido os benefícios do aleitamento materno para a saúde da criança. Realizou-se este estudo com o objetivo de avaliar o crescimento e a concentração de hemoglobina de crianças alimentadas exclusivamente ao seio até os 6 meses. Métodos: Estudou-se quatro grupos de crianças com idades de 0, 1, 3 e 6 meses nascidas no Hospital Guilherme Álvaro de Santos - São Paulo e matriculadas no Centro de Lactação localizado neste hospital. Utilizou-se para o estudo do crescimento o indicador peso para idade, tendo como referência o padrão do NCHS e os padrões desenvolvidos com crianças amamentadas brasileiras e do WHO Working Group on Infant Growth. Para a avaliação da concentração de hemoglobina, utilizou-se a curva proposta por Brault-Dubuc e colaboradores e foi adotado $10,5 \mathrm{~g} / \mathrm{dL}$ como o valor mínimo esperado para a hemoglobina. Resultados: As crianças apresentaram crescimento adequado quando comparado com os padrões utilizados. A curva de hemoglobina apresentou a mesma tendência da curva usada como padrão, sendo que os níveis de hemoglobina das crianças estudadas foram mais baixos. $O$ percentual de crianças com níveis de concentração de hemoglobina abaixo de $10,5 \mathrm{~g} / \mathrm{dL}$ foi de $71,7 \%$ aos 3 meses e de $56,2 \%$ aos 6 meses. Nenhuma correlação foi encontrada entre o crescimento e os níveis de hemoglobina. Conclusões: As crianças alimentadas exclusivamente com leite materno durante 0 primeiro semestre de vida apresentaram crescimento adequado. Entretanto, aos seis meses encontrou-se elevado número de crianças anêmicas. 
Descritores: Aleitamento materno, crescimento, hemoglobina, saúde infantil, reserva de ferro, anemia. 


\section{SUMMARY}

Objectives: The health benefits of breastfeeding for children are well documented. This study aims to evaluate the growth and the hemoglobin concentration on breast-fed infants up to the age of 6 months. Methods: This study was applied to four groups of children with different ages: 0, 1, 3 and 6 months old born at Guilherme Álvaro Hospital, in Santos City, State of São Paulo, and registered at the Lactation Center at that hospital. As far as the growth study is concerned, the weight-for-age indicator was used, evaluated with the current NCHS-WHO reference and with growth patterns developed on Brazilian breast-fed children as well as the WHO Working Group of Infant Growth. The hemoglobin concentration evaluation was done through the curve proposed by Brault-Dubuc and collaborators and an hemoglobin minimum value of $10,5 \mathrm{~g} / \mathrm{dL}$ was adopted. Results: Children presented adequate growth as compared with used standards. The hemoglobin curve presented the same pattern of the one used as standard, but the values obtained for the studied children were lower. Hemoglobin level below $10,5 \mathrm{~g} / \mathrm{dL}$ was found on $71,7 \%$ of the 3 months old children and $56,2 \%$ of the 6 months old children. No association was found among the growth and the hemoglobin concentration level. Conclusions: The exclusive breast-fed children during the first semester presented adequate growth. However, at six months was found higher number of anemic children. 
Descriptors: Breast-feeding, growth, hemoglobin child health, iron status anemia. 


\section{ÍNDICE}

página

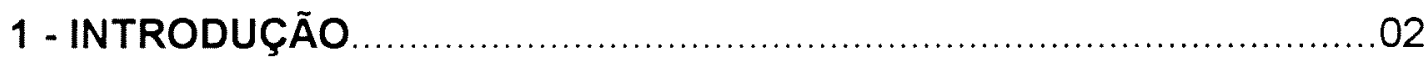

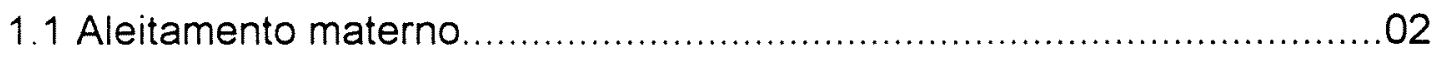

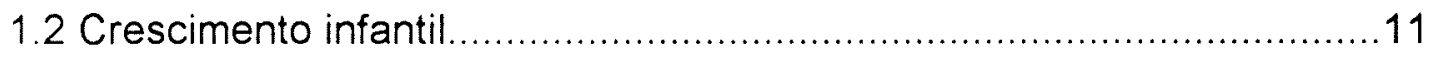

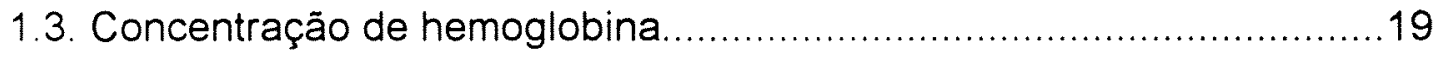

2. OBJETIVOS

3. METODOLOGIA

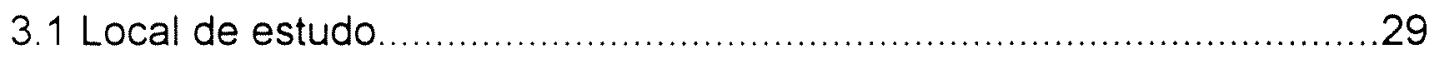

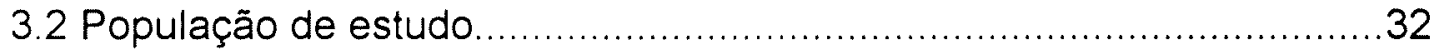

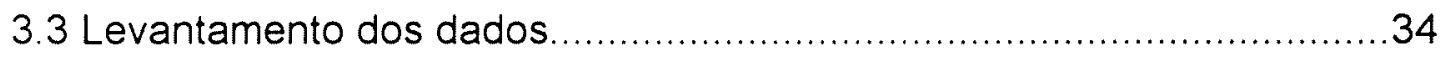

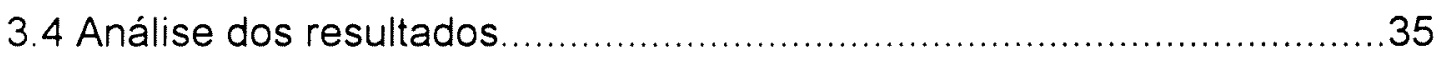

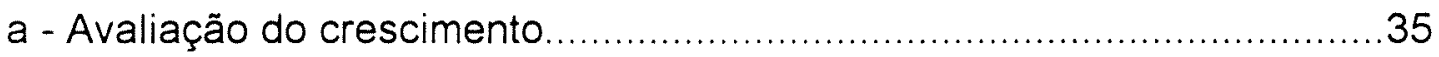

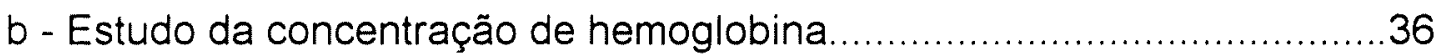

4. RESULTADOS

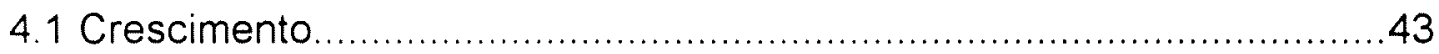

4.2 Nivel de concentração de hemoglobina...............................................50

5. DISCUSSÃO

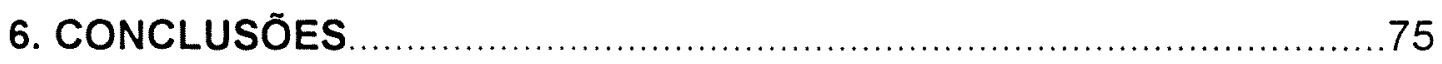

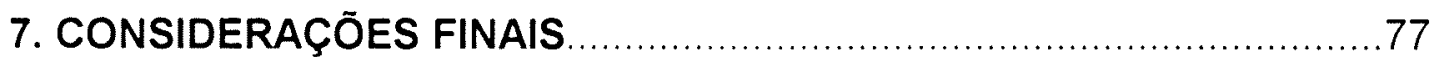

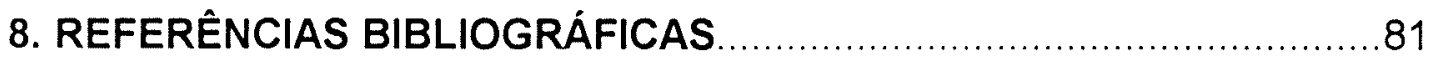

ANEXOS 


\section{LISTA DE TABELAS E FIGURAS}

página

Tabela 1 - Distribuição das crianças por sexo e idade. Centro de Lactação de Santos - SP, 1995/96.

Tabela 2 - Média e desvio padrão do peso ao nascer por idade. Centro de Lactação de Santos - SP, 1995/96.

Tabela 3 - Distribuição das crianças segundo o peso ao nascer Centro de Lactação de Santos - SP, 1995/96.

Figura 1 - Distribuição do índice escore-z (peso/idade) de crianças de 0 a 6 meses de idade. Centro de Lactação de Santos - SP. 1995/96.

Tabela 4 - Média e mediana de peso no momento da colheita de sangue. Centro de Lactação de Santos - SP, $1995 / 96$.

Tabela 5 - Média de ganho de peso no periodo estudado.

Centro de Lactação de Santos - SP, $1995 / 96$.

Figura 2 - Média de escore $Z$ (peso/idade) de crianças de 0 a 6 meses. Centro de Lactação de Santos - SP.

$1995 / 96$

Figura 3a - Comparação do peso médio para idade de meninos com aleitamento materno exclusivo. Centro de Lactação de Santos - SP. 1995/96.......

Figura 3b - Comparação do peso médio para idade de meninas com aleitamento materno exclusivo. Centro de Lactação de Santos - SP. 1995/96.

Figura 4a - Comparação do peso médio para idade de meninos com aleitamento materno. Centro de Lactação de Santos - SP, 1995/96. 
Figura 4b - Comparação do peso médio para idade de meninas com aleitamento materno. Centro de Lactação de Santos - SP, 1995/96

Tabela 6 - Valores médios e desvios padrão da concentração de hemoglobina segundo a idade. Centro de Lactação de Santos - SP, 1995/96.

Figura 5 - Médias das concentrações de hemoglobina de crianças de 0 a 6 meses em aleitamento materno exclusivo.

Centro de Lactação de Santos - SP, 1995/96

Tabela 7 - Distribuição das crianças segundo a concentração de hemoglobina e idade. Centro de Lactação de Santos - SP, 1995/96.

Figura 6 - Correlação do peso ao nascer $(\mathrm{Kg}) \mathrm{com}$ a concentração de hemoglobina $(\mathrm{g} / \mathrm{dL})$ de crianças recém-nascidas.

Centro de Lactação de Santos - SP, 1995/96.

Figura 7 - Correlação do peso ao nascer $(\mathrm{Kg})$ com a concentração atual de hemoglobina $(\mathrm{g} / \mathrm{dL})$ de crianças de 0 a 6 meses.

Centro de Lactação de Santos, SP, 1995/96.

Figura 8 - Correlação de ganho de peso $(\mathrm{Kg})$ com a concentração atual de hemoglobina $(\mathrm{g} / \mathrm{dL})$ de crianças de 0 a 6 meses.

Centro de Lactação de Santos - SP, 1995/96.

Tabela 8 - Distribuição das crianças segundo a concentração estimada de hemoglobina e a concentração medida, em g/dL. Centro de Lactação de Santos - SP, 1995/96.

Tabela 9 - Distribuição das gestantes, segundo a concentração de hemoglobina. Maternidade do Hospital Guilherme Álvaro. Município de Santos - SP, 1995/96. 
1

INTRODUÇÃO 


\section{INTRODUÇÃO}

Este estudo pretende analisar como se comportam alguns fatores relacionados ao crescimento e à concentração de hemoglobina em lactentes menores de seis meses aleitados exclusivamente ao seio. Para introduzir o assunto e justificar o estudo, este capitulo aborda aspectos do conhecimento sobre o aleitamento materno, do crescimento infantil e da concentração de hemoglobina.

Para designar o "lactente" usaremos de agora em diante a palavra "criança".

\subsection{Aleitamento materno}

Durante milhões de anos a alimentação ao seio representou a forma natural e praticamente única de se alimentar uma criança nos primeiros meses de vida (JELLIFFE e JELLIFFE 1978a).

O aleitamento materno é uma interação complexa entre mãe e criança que pode ser realçada ou inibida por um grande número de fatores sociais, fisiológicos e psicológicos (WINIKOFF e BAER 1980).

A qualidade do leite humano é descrita em exaustiva revisão por AKRÉ (1989), o qual enfatiza que este alimento é único quer na prevenção de infecções e alergias, quer no estímulo ao desenvolvimento do sistema imunológico da criança. Esse alimento tem sido reconhecido como de fundamental importância para o desenvolvimento da criança, especialmente em ambientes onde as condições sanitárias são precárias, reduzindo de forma significativa, a morbimortalidade no primeiro ano de vida (PLANK e 
MILANESI 1973; JASON e col. 1984; FEACHEM e KOBLINSKY 1984; HABICHT e col. 1986; BARROS Fo e col. 1985; SOUZA 1987; VICTORA e col. 1987; MARTINES e col. 1989; BRADY 1990; JOLLY 1990; CHAVES e col. 1995; FUCHS e col. 1996). Em populações de baixo nível sócioeconômico, ficou demonstrado que quanto mais nova a criança e maior o período de amamentação, maior a proteção conferida pelo leite materno (HABICHT e col. 1986; VICTORA e col. 1987).

No Brasil, o aumento da duração da mediana da amamentação de 84 para 146 dias, descrito por MONTEIRO e col. (1990) no município de São Paulo, pode ter sido responsável pela redução de $25 \%$ na taxa de mortalidade infantil no periodo de 1981 a 1987. VICTORA e col. (1987), em um levantamento no sul do pais, encontraram risco de mortalidade por diarréia 4,2 vezes maior em crianças alimentadas com leite materno e suplemento (fórmulas ou leite de vaca) quando comparadas àquelas em aleitamento materno exclusivo. Em outro estudo, VICTORA e col. (1992) evidenciaram o risco de morte por diarréia até 20 vezes maior em crianças completamente desmamadas antes dos 2 meses de idade.

O Programa de Controle de Doenças Diarréicas da Organização Mundial de Saúde - OMS recomenda que a amamentação seja promovida como uma das mais importantes medidas para prevenir a diarréia. Existem hoje evidências claras de que a amamentação confere proteção significativa contra as morbimortalidades relacionadas com a diarréia, diminuindo seus efeitos nutricionais adversos. 
JORGE JOÃO e SIMAS (1983) e VICTORA e col. (1984) encontraram mais um efeito protetor atribuido ao leite materno: a associação positiva com o estado nutricional de crianças brasileiras. CASTILLO e col. (1996), ao estudarem o padrão alimentar de 9.330 crianças chilenas menores de 18 meses, registraram uma superioridade do estado nutricional nas crianças amamentadas.

As taxas de morbidade e mortalidade das crianças amamentadas, nos países desenvolvidos são geralmente citadas como similares às das crianças alimentadas artificialmente, enquanto que nos paises em desenvolvimento, as crianças amamentadas apresentam taxas menores (AHN e MACLEAN 1980). No entanto, a crença generalizada de que o leite humano confere benefícios somente para as crianças dos países em desenvolvimento é desmentida pelos dados publicados nos últimos anos. FORD e LABBOK (1993), ao estudarem uma grande amostra nacional de crianças americanas, afirmaram que o aleitamento materno forneceu proteção contra a pneumonia e otite média. WALKER (1993) destacou importantes riscos atribuídos à alimentação artificial encontrados em diversos trabalhos com crianças de paises industrializados. Esses dados ratificam os resultados encontrados no estudo de CUNNIGHAM em 1977, também em paises industrializados, que mostrou taxas menores de morbidade entre as crianças amamentadas.

Os padrōes de amamentação apresentam-se de formas diversas nos diferentes paises e mesmo dentro de cada pais. Estudos coordenados pela 
OMS mostraram que em geral a amamentação é mais prolongada nos paises em desenvolvimento, onde grande número de crianças é amamentada por mais de 12 meses, enquanto que nos paises europeus este fato raramente ultrapassa os 6 meses (OMS 1981).

Apesar dos múltiplos atributos do aleitamento materno, a prática de amamentar tem sofrido importantes modificações.

A evolução do aleitamento materno nos paises desenvolvidos é bem conhecida (JELLIFFE e JELLIFFE 1978a; OMS/UNICEF 1980). O declínio do aleitamento começou nos centros urbanos no final do século 19 , estendendo-se progressivamente à zona rural. Essa tendência ampliou-se de tal modo, que tornou o desmame precoce e a alimentação artificial práticas habituais no século 20. Nos Estados Unidos e no oeste europeu, a fase dramática desse declínio aconteceu nos anos 30 e 40, durando esta tendência até os anos 60. Foi na década de setenta, que as campanhas de promoção de aleitamento materno, realizadas nesses países, proporcionaram uma crescente tomada de consciência acerca dos benefícios da amamentação, produzindo um retorno da prática de amamentar, com maior aceitação entre mulheres de melhor nivel sócioeconômico (VAHLQUIST 1975; MARTINEZ e NALEZIENSKI 1979; BIERING-SORENSEN e col. 1980; WINIKOFF e BAER 1980).

Os dados disponiveis a respeito da evolução da amamentação nos países em desenvolvimento são escassos. O declinio do aleitamento materno nesses paises começou somente depois da $2^{\mathrm{a}}$ Grande Guerra, coincidindo 
com a política de suplementação alimentar implementada por órgãos internacionais, que incluia a distribuição de leite em pó para crianças. A intensidade desse declínio variou em cada pais, mas foi geralmente mais forte entre as mulheres residentes em áreas urbanas e de melhor nivel sócioeconômico (JELLIFFE e JELLIFFE 1978a; OMS/UNICEF 1980; NOTZON 1984; MONTEIRO e REA 1988).

Nas décadas de 60 e 70 foram intensificados os estudos sobre os efeitos do desmame precoce, relacionado-o às altas taxas de mortalidade e morbidade associadas ao uso de mamadeira e leite artificial. Os resultados desses estudos, cada vez mais densos e criticos, despertaram o movimento de retorno à amamentação.

VENÂNCIO (1996), analisando a evolução da prática do aleitamento materno no Brasil, encontrou uma tendência ascendente nas décadas de 70 e 80 confirmando os achados encontrados anteriormente no pais por MONTEIRO e col. (1987), de que o aumento acentuado na prática de amamentação ocorreu, especialmente, entre as mulheres de maior poder aquisitivo e/ou de maior escolaridade.

O declínio da amamentação é explicado pela interação complexa de diversos fatores sócioculturais, variando a importância de cada um desses fatores segundo o pais e mesmo dentro de um determinado pais.

Diversos estudos realizados nos paises desenvolvidos e nos em desenvolvimento apontam como fatores envolvidos na queda do aleitamento materno: a incorporação da mulher ao trabalho fora de casa e a 
disponibilidade de substitutos do leite materno no mercado (MARTINEZ e NALEZIENSKI 1979; NOTZON 1984).

JELLIFFE e JELLIFFE (1978a) citam como um dos principais fatores que contribuiram para o abandono da amamentação, a mudança de culturas rurais tradicionais para um modo de vida urbana.

A Organização Mundial da Saúde - OMS e o Fundo das Nações Unidas para a Infância - UNICEF estimam em mais de 1 milhão o número de crianças que poderiam deixar de morrer anualmente se a prática do aleitamento materno exclusivo até pelo menos quatro meses fosse uma realidade. AKRÉ (1989) enfatiza que do ponto de vista da maturação fisiológica e da necessidade nutricional é desnecessário dar para a criança antes dos 4 meses outros alimentos além do leite materno.

A literatura científica aponta, com bastante freqüência, que a relação entre nivel sócioeconômico e a prática do aleitamento materno é positiva nos países desenvolvidos e negativa nos paises em desenvolvimento. SIGULEM e TUDISCO encontraram, em 1980, este resultado no estudo sobre o aleitamento natural com mulheres de diferentes classes de renda, no município de São Paulo. Alguns anos depois, BARROS e col. (1986), em Pelotas, Rio Grande do Sul e MONTEIRO e col. (1988), no município de São Paulo, encontraram a relação positiva entre nivel sócioeconômico e aleitamento materno, relatada como uma característica dos países desenvolvidos. 
Estes fatos justificam os grandes esforços que vêm sendo realizados no plano mundial nas duas últimas décadas para promover, apoiar e proteger a amamentação.

A promoção do aleitamento materno ocupa lugar de destaque entre as ações básicas de saúde recomendadas pela OMS para diminuir a morbidade e a mortalidade e melhorar a qualidade de vida das crianças dos paises em desenvolvimento. Os conhecimentos cientificos relacionados às qualidades nutricionais e anti-infecciosas do leite humano justificam o esforço gasto com esta atividade, em especial nos locais onde a desnutrição e as infecções de repetição aparecem como sério problema de saúde pública, que é agravado pelo restrito acesso da população pobre aos serviços de saúde. A OMS recomenda que as crianças sejam alimentadas exclusivamente com leite materno nos primeiros 4 a 6 meses de vida e que continuem a receber este leite até os dois anos de idade, complementado por outros alimentos (WHO 1991).

WINICOFF e BAER (1980) afirmam que uma Política de Saúde, encorajando o aleitamento materno na comunidade e nos hospitais, realizada com o auxílio dos profissionais de saúde, pode aumentar a incidência e duração do aleitamento materno.

No Brasil, no início dos anos 80 , foi criado pelo Ministério da Saúde o Programa Nacional de Incentivo ao Aleitamento Materno (PNIAM), com o objetivo de estimular e prolongar a duração do aleitamento natural. Entre suas atividades, podem ser citadas o estímulo à formação de grupos de 
incentivo ao aleitamento materno em todo o país e a campanha veiculada na televisão, no rádio e na imprensa gráfica, com mensagens feitas por artistas de destaque, apresentando as vantagens da amamentação.

Num estudo realizado em São Paulo, REA (1990) mostrou que uma campanha bem organizada, através da mídia, pode ter efeito mensurável e positivo na amamentação.

O aumento da duração do aleitamento materno e do número de crianças amamentadas no momento da alta hospitalar na Grande São Paulo, identificados no final da década de 80 por REA e BERQUÓ (1990), são citados entre os primeiros resultados positivos do PNIAM.

A visita domiciliar pós-parto, uma das ações integrantes dos programas de saúde, foi apontada por BARROS e col. (1994) como outra medida positiva para incrementar o aleitamento materno nos primeiros meses de vida, com a vantagem, referida pelos autores, do baixo custo deste tipo de intervenção.

Uma das formas de promover o aleitamento materno é através de "CENTROS DE LACTAÇÃO" que fornecem assistência à mãe e treinamento para profissionais de saúde. O modelo destes Centros foi desenvolvido em San Diego (Wellstart Lactation Program), Estados Unidos e a partir de 1990 vem sendo implementado no Brasil (BARROS e cols. 1995).

O resultado do trabalho desenvolvido num Centro de Lactação foi descrito por BARROS e col. (1995) apontando maior duração do aleitamento materno exclusivo, menor freqüência de diarréia e melhor crescimento, em crianças atendidas no Centro de Lactação do Guarujá - São Paulo, quando 
comparadas com crianças que não freqüentaram o Centro. Os autores afirmam que os Centros de Lactação são efetivos na promoção do aleitamento materno e recomendam seu uso em áreas onde é curta a duração da amamentação. 


\subsection{Crescimento infantil}

O crescimento é um processo complexo que sofre rápidas mudanças durante a infância, sendo afetado direta e/ou indiretamente por diversos fatores como o sexo, o tamanho ao nascer, os padrões alimentares e 0 potencial genético. Esses fatores, por sua vez, são determinados por condições sócio-econômicas, culturais e biológicas (UNDERWOOD e HOFVANDER 1982; SEWARD e SERDULA 1984).

A avaliação do crescimento é uma medida simples que melhor define a saúde e o estado nutricional da criança, porque os distúrbios na saúde e no estado nutricional, sem considerar a sua etiologia, afetam invariavelmente o crescimento infantil (ONIS e HABICHT 1996).

Os fatores nutricionais podem afetar o crescimento da criança antes e depois de seu nascimento. A nutrição da mãe e da criança estão interrelacionadas desde a concepção até o momento do desmame completo, sendo o consumo dietético da gestante e da mulher que amamenta de suma importância (JELLIFFE e col. 1972; JELLIFFE e JELLIFFE 1978b).

Paralelamente aos fatores nutricionais, as infecções, principalmente as gastroenterites, aparecem como um dos principais fatores não relacionados com a dieta que afetam o crescimento de crianças dos paises em desenvolvimento (SCRIMSHAW e col. 1968). 
Como já descrito, os benefícios do aleitamento materno para a saúde e o crescimento infantil são bastante conhecidos, particularmente nos países em desenvolvimento, onde ele pode ser a única forma de evitar a desnutrição e o conseqüente aumento do risco de morbimortalidade no primeiro ano de vida.

As necessidades nutricionais da criança aumentam com o crescimento e a maneira ideal para alimentá-la varia com a idade.

A política oficial da OMS e do UNICEF considera que o leite materno é o alimento ideal para a criança e afirma que o aleitamento exclusivo é suficiente para cobrir suas necessidades durante os primeiros 4 a 6 meses de vida.

Os Ministérios da Saúde de muitos países em desenvolvimento, juntamente com a OMS e o UNICEF, promovem o incentivo ao aleitamento materno, afirmando que as mulheres deveriam amamentar os seus bebês o maior tempo possivel (GRANT 1988).

Várias controvérsias são relatadas sobre o padrão de crescimento nos primeiros 6 meses de vida (WATERLOW e THOMSON 1979; WATERLOW e col. 1980; HITCHCOCK e col. 1981), e sobre a adequação nutricional do leite materno (JELLIFFE e JELLIFFE 1978b; JELLIFFE e JELLIFFE 1979; ROWLAND e col. 1981).

Para alguns pesquisadores, o aleitamento materno fornece todos os nutrientes necessários até os três meses, mas depois desta idade, na maioria dos casos não garante um crescimento adequado. 
WATERLOW e THOMSON (1979) ao estudarem a adequação do leite materno, mostraram que a quantidade de proteína é suficiente até os 6 meses e que a quantidade de energia torna-se inadequada entre o terceiro e o quarto mês de vida da criança, conclusão semelhante à de WHITEHEAD e PAUL (1981). Segundo SEWARD e SERDULA (1984), o leite materno sozinho não garante o crescimento adequado da criança após os 6 meses.

Outros estudiosos consideram ainda que as crianças alimentadas exclusivamente com leite materno podem precisar de suplemento, se o seu crescimento for avaliado de acordo com o padrão do NATIONAL CENTER FOR HEALTH STATISTICS - NCHS (WHITEHEAD E PAUL 1984; DEWEY E col. 1992a).

BUTTE e col. (1984), num estudo com 45 crianças americanas alimentadas exclusivamente com leite materno, verificaram que aos 4 meses elas estavam consumindo $71 \mathrm{kcal} / \mathrm{kg} / \mathrm{dia}$, valor este que corresponde a $62 \%$ daquele recomendado pela FAOMHO (1973). Eles comentam que a quantidade de leite normalmente produzido pelas mães é insuficiente para atender à recomendação e afirmam que as necessidades nutricionais durante a infância são baseadas em observações empíricas relativas ao consumo de crianças saudáveis.

O fato de que, nos paises em desenvolvimento, o ganho de peso das crianças amamentadas começa a diminuir aos 2 ou 3 meses (HABICHT e col. 1974; WATERLOW e col. 1980) e que nos paises industrializados esta 
queda acontece entre 4 e 6 meses (WHITEHEAD e PAUL 1981; SALMENPARÄ e col. 1985) merece, segundo WATERLOW (1996), uma atenção especial.

Tem sido bastante discutido entre os pesquisadores e continua sendo um ponto polêmico a resposta para a pergunta: "Durante quanto tempo o leite materno, como única fonte de alimento da criança, garante um crescimento adequado?" (WATERLOW e THOMSON 1979; HITCHCOCK e col. 1981; SEWARD e SERDULA 1984; DEWEY e col. 1992b; DIAZ e col. 1995; WATERLOW 1996).

A idade ideal para se iniciar a introdução de alimentos está relacionada com fatores como o estado de saúde e nutrição da mãe; quantidade e qualidade de leite materno produzido; o peso e a idade gestacional ao nascer e a saúde da criança. Devido a todos esses fatores o momento no qual o aleitamento materno exclusivo não consegue mais atender às necessidades nutricionais adequadas a um crescimento infantil satisfatório, varia entre populações e mesmo entre grupos de uma mesma população (SEWARD e SERDULA 1984).

Dois tipos de levantamento são utilizados para avaliar a adequação do aleitamento materno necessário para um crescimento infantil satisfatório: utilização de cálculos teóricos das necessidades de energia e proteína, comparados com a produção de leite materno, e a performance do crescimento infantil comparado com populações de referência. 
Muitos estudos que avaliam o efeito das práticas alimentares no crescimento utilizam medidas antropométricas para determinar a adequação da alimentação infantil. As mais utilizadas são o peso para idade $(P / I)$ e a altura para idade (A/I). O peso para idade reflete o estado nutricional atual e apresenta inúmeras vantagens, entre elas, o fato de ser mais fácil de medir e interpretar e poder ser medido por pessoa pouco habilitada. A altura para idade, por sua vez, é afetada pelo padrão alimentar da criança depois de um longo periodo de tempo e requer pessoal melhor treinado para sua medida. O padrão de alimentação pode afetar essas medidas de diversas formas.

As técnicas utilizadas para obtenção de peso e altura são relativamente precisas, entretanto a interpretação adequada do crescimento infantil é bastante complexa, dependendo do padrão de crescimento e dos pontos de corte adotados. Uma interpretação apropriada deve levar em consideração: a escolha do padrão; a adequação das referências de crescimento utilizadas atualmente para crianças alimentadas exclusivamente ao peito; o crescimento de crianças pequenas para idade gestacional e por último a medida de peso observada num determinado momento versus o incremento de peso num intervalo de tempo (SERWARD e SERDULA 1984).

O NATIONAL CENTER FOR HEALTH STATISTICS (NCHS 1977) é o padrão recomendado para uso internacional pela OMS, permitindo comparações de dados entre diferentes populações. 
Todos os padrões de referência até hoje conhecidos, inclusive o NCHS, e o padrão de Santo André feito com crianças brasileiras (MARCONDES e col. 1971) basearam-se, predominantemente, nas medidas de crianças alimentadas artificialmente, que tiveram uma introdução precoce de alimentos sólidos e que apresentaram um crescimento mais rápido em relação ao das crianças alimentadas com leite materno nos primeiros 6 meses de vida. O uso desses padrões, para avaliação do crescimento de crianças com aleitamento materno exclusivo, pode não ser apropriado segundo diversos pesquisadores (JELLIFFE e JELLIFFE 1978b; HITCHCOCK e col. 1981; CHANDRA 1982; WHITEHEAD e col. 1984; SALMENPERÄ e col. 1985; MURAHOVSCHI e col. 1987; DEWEY e col. 1992a; DEWEY e col. 1992b; WATERLOW 1996; VICTORA e col. 1998a).

Os estudos sobre o crescimento de crianças alimentadas com leite materno, de forma exclusiva ou predominante, têm sido realizados em países desenvolvidos e em desenvolvimento, onde os fatores que influenciam o crescimento variam muito.

HITCHCOCK e col. (1981) afirmam que a avaliação de trabalhos sobre o crescimento infantil disponiveis na literatura é uma tarefa muito difícil, porque as populações estudadas são diferentes das populações de referência em termo de raça e condição sócioeconômica. UNDERWOOD e HOFVANDER (1982) lembram, também, os problemas com a casuística dos estudos, principalmente quando estes são transversais. 
SEWARD e SERDULA (1984)numa ampla revisão de trabalhos sobre o crescimento e a alimentação infantil afirmam que nos países desenvolvidos, numa situação ideal, onde a mãe e a criança são bem nutridas e saudáveis, o leite materno sozinho fornece um crescimento semelhante ao de qualquer população de referência até os 3 meses e depois apresenta um ligeiro declive entre os 3 e 6 meses. Nos paises em desenvolvimento, as crianças que são predominantemente alimentadas com leite materno tiveram incrementos de peso do 0 aos 6 meses similares aos das crianças dos paises desenvolvidos (ligeiramente maior no primeiro trimestre e ligeiramente menor no segundo trimestre).

A semelhança observada no padrão de crescimento de crianças de países desenvolvidos, e de crianças de nível sócio-econômico elevado dos paises em desenvolvimento, é sem dúvida alguma resultado de uma nutrição adequada, de melhores condições ambientais e do menor retardo de crescimento relacionado com as infecções. Porém, este não é o padrão de crescimento que as crianças dos paises em desenvolvimento normalmente apresentam (SEWARD e SERDULA 1984).

O significado para a saúde do insuficiente ganho de peso em relação ao valor da mediana da população de referência, observado entre os três e seis meses, tanto para as crianças dos países em desenvolvimento como para as crianças dos paises desenvolvidos, não é conhecido, mas com certeza, é potencialmente mais sério para as crianças dos países em desenvolvimento (SEWARD e SERDULA 1984). 
Vem sendo considerado um fator de grande importância para o Expert Committe da World Health Organization - WHO, o fato de que o crescimento de crianças alimentadas com leite materno, morando em condições favoráveis de diversas áreas geográficas, seja inferior ao da população de referência do NCHS, principalmente depois do primeiro trimestre. Esta aparente alteração no crescimento pode conduzir a decisōes errôneas, levando à complementação do aleitamento materno ou mesmo a sua interrupção. Este fato é de importância relevante, principalmente nos paises em desenvolvimento onde, como já foi comentado anteriormente, o aleitamento materno é o responsável pela sobrevivência das crianças ou, pelo menos, aparece como um fator que limita o aparecimento de doenças infecciosas (WHO 1995). 


\subsection{Concentração de Hemoglobina}

Cerca de $96 \%$ do peso do corpo humano é constituido por apenas cinco elementos químicos (carbono, hidrogênio, oxigênio, nitrogênio e enxofre). Os $4 \%$ restantes, que desempenham o papel de reguladores das funções vitais orgânicas, são formados pelos macrominerais, microminerais e elementos traço. Entre os microminerais, o ferro é o que desperta maior atenção, por sua carência ser responsável pelo problema nutricional de maior prevalência, atingindo milhões de individuos em todo $\circ$ mundo (DeMAEYER e ADIELS-TEGMAN 1985).

O homem adulto tem de 3 a $5 \mathrm{~g}$ de ferro corporal total distribuídos entre 0 ferro funcional e o de estoque. A maior parte do ferro (60-70\%) está contida na hemoglobina, elemento responsável pelo transporte do oxigênio, encontrada nos glóbulos vermelhos; 10 a 12\% estão na mioglobina e 16 a $29 \%$ estão na forma de ferritina e hemosiderina, que constituem a forma de armazenamento (INACG 1977)

A carência de ferro atinge, em maior ou menor grau, todas as células de um organismo vivo e se traduz por uma enfermidade sistêmica com múltiplos sintomas, dependendo dos órgãos afetados (TABOADA 1983). A deficiência sistêmica do ferro no organismo humano ocorre de forma gradual e progressiva, resultando na anemia.

O desenvolvimento da deficiência de ferro pode ser dividido em 3 momentos: primeiro ocorre a depleção dos estoques de ferro, depois a diminuição do transporte de ferro circulante e por último a diminuição da 
produção da hemoglobina. Este estágio ocorre quando o fornecimento de ferro está diminuido a ponto de tornar-se um fator limitante para formação de hemoglobina dos glóbulos vermelhos (MONZON 1985).

Anemia nutricional foi definida pela OMS em 1968, como um "estado em que a concentração de hemoglobina sangüínea situa-se abaixo do normal em conseqüência da carência de um ou mais nutrientes essenciais qualquer que seja a origem desta carência". A mais freqüente é o resultado de uma severa deficiência de ferro. Em saúde pública, o termo anemia refere-se à anemia ferropriva ou anemia por deficiência de ferro, visto ser esta a causa mais comum da doença (OMS 1968; DeMAEYER e ADIELS-TEGMAN 1985). A anemia ferropriva ocorre como resultado de um desequilíbrio no balanço entre a quantidade de ferro biologicamente disponível e sua necessidade orgânica (FINCH e COOK 1984).

Segundo estimativas da OMS, a anemia por deficiência de ferro afeta $30 \%$ da população mundial e $43 \%$ das crianças nos primeiros anos de vida (DeMAEYER e ADIELS - TEGMAN 1985). Estas crianças, juntamente com as gestantes, constituem o grupo mais vulnerável à anemia por deficiência de ferro (DeMAEYER e ADIELS - TEGMAN 1985; DeMAEYER e col. 1989). $\mathrm{Na}$ infância, a anemia ferropriva ocorre, principalmente, devido ao aumento das necessidades de ferro, imposto pela rápida expansão da massa celular vermelha e pelo crescimento acentuado dos tecidos (INACG 1979).

A Organização Mundial da Saúde, em 1975, relata que a deficiência de ferro moderada, mesmo na ausência de anemia, representa um considerável 
agravo à saúde (OMS 1975). Segundo DeMAEYER e col. (1989) ela provoca alteração no desempenho comportamental, causa prejuízos na capacidade de aprendizagem e prejudica o crescimento da criança. WALTER e col. (1989) e LOZOFF e col. (1991) afirmaram que a deficiência de ferro num período de crescimento e diferenciação do cérebro pode provocar danos irreversiveis.

O conhecimento da etiologia da anemia no primeiro ano de vida é fundamental, visto que as maiores prevalências desta deficiência nutricional ocorrem até os dois anos (MONTEIRO e SZARFARC 1987).

Os fatores relacionados com a etiologia da anemia e que determinam as necessidades de ferro na criança menor de um ano são: as reservas de ferro ao nascer, a velocidade de crescimento, a quantidade de ferro total da dieta e as perdas do mineral (STEKEL 1984a, 1984b).

A quantidade de ferro que o feto acumula durante a vida intra-uterina é proporcional ao seu aumento de peso. Ao nascer, a criança a termo tem cerca de $75 \mathrm{mg}$ de ferro por quilo de peso, dos quais $2 / 3$ se encontram sob a forma de hemoglobina, constituindo uma verdadeira reserva de ferro (STEKEL 1984b; OSKI e NAIMAN 1984). Quanto menor o peso de nascimento mais baixa será a quantidade orgânica de ferro.

Nos dois primeiros meses de vida ocorre um declínio acentuado na concentração de hemoglobina, em função da transformação da hemoglobina fetal em hemoglobina adulta. Neste momento, a concentração de hemoglobina alcança os valores mais baixos observados durante todo 0 
periodo de desenvolvimento infantil. Esse declinio, designado "anemia fisiológica da infância", independente de fatores nutricionais e é atribuído a um repentino declinio na eritropoiese em resposta à aumentada saída pósnatal do oxigênio para os tecidos (OSKI e NAIMAN 1984; MONZON 1985). Aos 6 meses a hemoglobina alcança um platô que é mantido até o final da infância.

Durante o primeiro semestre, o lactente utiliza as reservas de ferro acumuladas na fase intra-uterina para suprir as necessidades do nutriente, impostas pelo crescimento e pela reposição das perdas basais (DeMAEYER e col. 1989). A maior velocidade de crescimento ocorre durante o primeiro ano de vida, periodo no qual a criança nascida a termo triplica o seu peso. As reservas de ferro se esgotam aproximadamente aos 4 meses de idade para estas crianças.

O rápido crescimento da criança a torna vulnerável à deficiência de ferro, principalmente na fase de diminuição das reservas deste nutriente e a alimentação passa a ter papel preponderante no atendimento de suas necessidades (STEKEL 1984b; DALLMAN 1985).

O leite materno, pobre em ferro, compensa esta carência com uma alta biodisponibilidade (50\% do ferro contido no leite materno são absorvidos), sendo o alimento mais adequado para fornecer esse mineral ao lactente (STEKEL 1984b).

SAARINEN e col. (1977) citam um trabalho realizado em 1931 por Mackay, no qual o autor relata a proteção encontrada em crianças amamentadas no 
que diz respeito à deficiência de ferro. Entretanto, os mesmos autores afirmam que existem escassas evidências que confirmem essa proteção.

Encontramos na literatura consultada contradições no que diz respeito ao ferro do leite materno como única fonte exógena, capaz de suprir a demanda infantil deste mineral. Enquanto MCMILLAN e col. (1976) e SIIMES e col. (1984) referem que o ferro do leite materno é suficiente para crianças em aleitamento materno exclusivo até o final do primeiro ano de vida e até os 9 meses, respectivamente, CALVO e col. (1992) verificaram que, apesar da alta biodisponibilidade, a quantidade de ferro do leite materno é insuficiente para atender à demanda deste mineral de uma criança com velocidade normal de crescimento, já a partir do $4^{\circ}$ mês de vida.

O número de estudos no Brasil sobre anemia é pouco expressivo e a maior parte deles diz respeito a grupos populacionais restritos (SIGULEM e col. 1978; SALZANO e col. 1985; MONTEIRO e SZARFARC 1987; SICHIERI 1987; VANNUCCHI e col. 1992; LERNER 1994; SOUZA 1994; STEFANINI e col. 1995; SZARFARC e col. 1996). Alguns desses estudos têm evidenciado a proteção conferida pelo aleitamento materno no que diz respeito à anemia em crianças durante o primeiro ano de vida, mas não são relacionados com crianças em aleitamento materno exclusivo.

MONTEIRO e SZARFARC (1987) num estudo epidemiológico sobre condições de saúde e nutrição de crianças de 0 a 60 meses realizado em 1984-85, no município de São Paulo, revelaram que as taxas mais elevadas de prevalência de anemia ocorreram entre as crianças menores de 2 anos e 
que, entre as menores de 6 meses, faixa de idade na qual a anemia ferropriva deveria ser muito rara, diagnosticou-se $34,7 \%$ de crianças com esta deficiência nutricional. A curta duração do aleitamento materno exclusivo, a introdução tardia de alimentos fonte de ferro e o consumo insuficiente e inadequado de estimuladores da absorção deste mineral foram as causas fundamentais, apontadas pelos autores, da prevalência de anemia que atingiu cerca de $50 \%$ das crianças menores de um ano.

Existe atualmente considerável evidência de que crianças alimentadas com leite materno apresentam um crescimento diferente de crianças alimentadas com leite artificial e que os padrões de crescimento disponíveis são inadequados para avaliar o crescimento de crianças amamentadas. Por sua vez, não existe ainda um consenso em relação a por quanto tempo o ferro do leite materno é suficiente para suprir as necessidades da criança, durante os primeiros meses de vida.

Sabe-se que o leite humano constitui o alimento específico para crianças, atendendo suas condições particulares de digestão e metabolismo, com vantagens indiscutiveis sobre a alimentação artificial. Entretanto, diante desta exposição, percebe-se que há controvérsias na literatura sobre até que periodo da vida a adequação do leite materno garante um crescimento infantil satisfatório. O desconhecimento a respeito do crescimento "ideal" de crianças aleitadas exclusivamente ao seio, tem sido apontado como uma das principais causas do desmame precoce que conduz a um aumento do risco de doenças infecciosas. Este fato, aliado à falta de conhecimento a 
respeito dos niveis de hemoglobina de crianças amamentadas e ao baixo teor de ferro do leite materno, levaram-nos à elaboração deste estudo sobre o crescimento e a concentração de hemoglobina em crianças alimentadas exclusivamente ao seio durante os primeiros 6 meses de vida, conforme recomendação da OMS. 


\section{2}




\section{OBJETIVOS}

\subsection{Geral}

- Analisar o crescimento e a concentração de hemoglobina de crianças alimentadas exclusivamente ao seio até os seis meses.

\subsection{Específicos}

- Identificar a evolução do crescimento e da concentração de hemoglobina, de crianças com aleitamento materno exclusivo nos primeiros seis meses de vida.

- Avaliar as relações entre o crescimento e a concentração de hemoglobina nas crianças estudadas. 


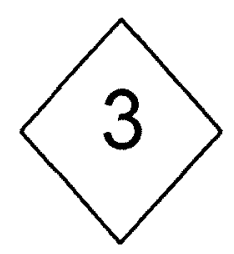

METODOLOGIA 


\section{METODOLOGIA}

Este trabalho faz parte de um projeto sobre aleitamento materno, dieta de desmame e evolução dos indicadores da situação orgânica de ferro realizado no município de Santos.

Para atender aos objetivos desta pesquisa trabalhou-se com crianças de zero a seis meses alimentadas exclusivamente com leite materno.

A pesquisa foi aprovada pela Comissão de Ética do Hospital Guilherme Álvaro e todas as atividades deste trabalho foram realizadas após a explicação à mãe sobre os objetivos da pesquisa e obtido seu consentimento para a participação da criança.

O estudo apresentou um desenho transversal. Considerou-se que, devido à homogeniedade das características da população, a evolução do crescimento pode ser tratada como a de uma coorte.

\subsection{Local de Estudo}

O estudo foi realizado no Centro de Lactação do Hospital Guilherme Álvaro, localizado no município de Santos.

O município de Santos situa-se no litoral do Estado de São Paulo, abrangendo uma área de $39,40 \mathrm{~km}^{2}$ da ilha de São Vicente e mais uma extensão continental onze vezes maior. Com cerca de 450 mil habitantes ele constitui o polo principal da região metropolitana da Baixada Santista. $\mathrm{Na}$ porção insular vivem $99 \%$ de sua população, com uma ocupação urbana 
intensa e verticalizada, que se reflete numa densidade populacional de 10.548,27 habitantes por $\mathrm{Km}^{2}$ (CAMPOS e HENRIQUES 1997).

Os dados do Censo de 91 mostraram a cidade de Santos com índices de saneamento básico bem superiores aos encontrados em outras localidades brasileiras: praticamente a totalidade dos domicilios $(98 \%)$ era coberta por rede de água e $92,5 \%$ por rede de esgoto. A renda média dos chefes de família, nessa ocasião, era similar à registrada no Município de São Paulo ( 7,0 salários mínimos).

A primeira metade da década de noventa é marcada, em Santos, por grandes investimentos realizados pela Administração Municipal nas áreas de saúde, saneamento e educação.

O programa de atendimento às gestantes e aos recém-nascidos, resultou em vários ganhos à saúde da criança. O mais importante deles foi a redução da mortalidade infantil, que em 1990 estava em torno de 33/1000 nascidos vivos e em 1995 passou para 24/1000 (CAMPOS e HENRIQUES 1997). Entre as ações de saúde desenvolvidas por meio deste programa nas Unidades Básicas, o incentivo ao aleitamento materno exclusivo mereceu destaque especial no município de Santos, como descrito a seguir.

O Hospital Guilherme Álvaro, é um hospital público estadual que vem funcionando desde 1967. Tem uma capacidade para 160 leitos, sendo 33 destinados à maternidade. Em 1973 tornou-se um hospital escola e incorporou na maternidade, a política de alojamento conjunto. Há mais de 20 anos esta instituição vem se destacando na área do aleitamento 
materno, através de iniciativas pioneiras, tendo sido contemplado pela UNICEF/OMS com o titulo de Hospital Amigo da Criança.

No referido hospital, um grupo de profissionais do Departamento de Pediatria da Faculdade de Ciências Médicas de Santos, com o apoio da Organização Mundial de Saúdel Organização Panamericana de Saúde (OMS/OPS - por meio do Programa de Controle de Doenças Diarreicas), do Instituto Nacional de Alimentação e Nutrição (INAN/ Ministério da Saúde) e do Instituto de Saúde (Secretaria de Estado da Saúde de São Paulo), criou em 1990 o Centro de Lactação. Sua criação foi baseada na proposta dos "CENTROS DE LACTAÇÃO" desenvolvida em San Diego - "Wellstart Lactation Program" nos Estados Unidos.

O Centro de Lactação de Santos dedica-se à promoção do aleitamento materno exclusivo até os 6 meses, ao treinamento de profissionais de saúde e à pesquisa sobre leite materno e técnicas de amamentação. Ele é considerado referência internacional para capacitação de profissionais de saúde em aleitamento materno, na América Latina e nos países de língua portuguesa da África.

O atendimento às crianças é feito uma vez por semana (quinta-feira), consiste de palestras, formação de grupos de mães para trocas de experiências sobre o aleitamento materno, seguido de consulta pediátrica individual. 


\subsection{População de Estudo}

A população de estudo foi constituída por crianças nascidas no Hospital Guilherme Álvaro da Faculdade de Ciências Médicas de Santos e matriculadas no Centro de Lactação de Santos, localizado nesse Hospital. Ao nascer, essas crianças estiveram em regime de alojamento conjunto e em aleitamento natural desde as primeiras horas de vida. Pertenciam à classe sócioeconômica baixa com renda familiar média de um a dois salários mínimos, de acordo com os critérios de admissão no Hospital.

No período de setembro de 1995 a setembro de 1996 foram selecionados quatro grupos de crianças. Os três primeiros, constituidos por diferentes crianças com idades de 1, 3 e 6 meses, que freqüentavam o Centro de Lactação. O último, composto por crianças recrutadas na maternidade do Hospital Guilherme Álvaro, na hora do parto (grupo de crianças com idade zero). A formação dos grupos foi iniciada pelo grupo de crianças com 6 meses, uma vez que, era sabidamente conhecida a existência de pequeno número de crianças desta idade freqüentando o Centro de Lactação. Pretendeu-se conseguir durante o periodo de estudo 50 crianças com aleitamento materno exclusivo, em cada grupo de idade estabelecido, totalizando 200 crianças.

A decisão de trabalhar com crianças atendidas num Centro de Lactação, cujas mães estão provavelmente mais motivadas para $\circ$ aleitamento materno exclusivo, foi intencional neste estudo. Com isto, esperava-se superar a dificuldade de encontrar número suficiente de crianças 
amamentadas exclusivamente ao seio por um periodo de tempo mais prolongado, dificuldade esta apontada em outros estudos (CUNNINGHAM 1977; De SWIET e col. 1977).

A seleção de todas as crianças seguiu os seguintes requisitos:

- nascidas a termo;

- com peso $\geq 2.600 \mathrm{~g}$, correspondente ao percentil 10 do NCHS (1977) e - que não apresentaram nenhuma doença grave no período considerado.

A conceituação de aleitamento materno exclusivo, adotada no Centro de Lactação de Santos, exclui tanto os líquidos (água, chás, sucos) como os alimentos semi-sólidos (papas de frutas, mingaus, sopas) e as mães são orientadas para amamentar a criança em horário e quantidades livres, como recomendado pela OMS.

Para confirmação da amamentação exclusiva ao seio no Centro de Lactação são observadas as seguintes normas:

- informações relacionadas aos cuidados com a criança, dadas pela mãe à atendente especialmente treinada, no momento da recepção e pesagem; - observação do aspecto característico das fezes;

- ato da amamentação durante a consulta e

- informações dadas pela mãe ao médico.

As crianças são agendadas para comparecerem ao Centro de Lactação uma vez por semana durante o primeiro mês de vida, a cada 15 dias no segundo mês, e uma vez por mês do terceiro ao sexto mês. 


\subsection{Levantamento dos Dados}

Foi colhida uma amostra de sangue venoso de cada criança que fez parte do estudo. A colheita de sangue foi feita, uma única vez por criança, nas idades previamente escolhidas (grupo de crianças com 0, 1, 3 e 6 meses). 0 sangue colhido na maternidade no momento do parto (grupo de criança na idade 0), teve além do consentimento prévio da mãe a autorização adicional do pediatra de plantão.

O diagnóstico da anemia foi feito através da dosagem da concentração de hemoglobina, medida pelo método da cianometahemoglobina (INACG 1985). As amostras foram colhidas por duas atendentes treinadas e encaminhadas na mesma hora para serem analisadas. Este trabalho ficou sob a responsabilidade da chefia do Laboratório de Análises Clínicas do Hospital.

O peso e o comprimento ao nascer, sexo e a data de nascimento foram recolhidos dos prontuários das crianças. As outras medidas de peso foram obtidas no mesmo momento estabelecido para a colheita de sangue, ou seja durante as consultas, nas visitas de rotina, das crianças com idades que interessavam ao estudo. Após a nossa observação sobre a qualidade e o controle realizado pelos médicos responsáveis pelo Centro de Lactação de Santos, que têm toda uma preocupação voltada para garantir subsídios que permitam a realização de pesquisas em aleitamento materno, consideramos a validade e confiabilidade das medidas adequadas. 
As crianças foram pesadas sem roupas, em balança pesa-bebê convenientemente aferida pelo pessoal de enfermagem do Centro de Lactação, treinado conforme técnicas padronizadas.

\subsection{Análise dos Resultados}

\section{a. Avaliação do crescimento}

O estudo do crescimento, realizado neste trabalho, diz respeito a evolução ponderal das crianças; utilizou-se o indice antropométrico peso para idade. Este indicador é a variável encontrada com maior freqüência nos estudos de crescimento, especialmente naqueles referentes aos efeitos das práticas alimentares no crescimento infantil (SEWARD e SERDULA 1984).

Quando não se conseguiu o peso nas datas programadas ( \pm 6 dias), 0 mesmo foi ajustado por interpolação. Foram ajustados $18,0 \%$ dos pesos.

Os pesos obtidos nas diferentes idades foram utilizados para se conhecer 0 perfil de crescimento durante os primeiros seis meses.

A população de referência foi a do National Center for Health Statistics NCHS (1977) conforme recomendação da OMS (WHO 1986).

Uma outra forma utilizada para descrever o crescimento da população em relação ao padrão foi o cálculo do escore $Z$ ( $n^{\circ}$ de desvios-padrão distantes da mediana da população de referência em relação ao peso da criança).

O uso do escore $Z$ tem sido recomendado por permitir a comparação nas diferentes idades e entre indices antropométricos distintos (WHO 1986). 
Utilizou-se o Programa para Antropometria Nutricional (EPINUT) do Center for Disease Control and Prevention (1990), incluido no pacote estatístico EPI INFO versão 6.0, para os cálculos antropométricos. As análises estatísticas foram feitas utilizando-se média, desvio padrão e para as medidas de associação utilizaram-se o teste qui-quadrado e o teste $T$ com nivel de significância de 5\%. Utilizou-se o programa Statistical Package for the Social Sciences - SPSS/PC for Windows, versão 7,0 (1996). Verificaram-se as relações entre peso e concentração de hemoglobina pela análise de correlação.

Para a avaliação do crescimento foram construídas curvas de peso nas diferentes idades que foram comparadas com as curvas de crescimento de lactentes brasileiros alimentados exclusivamente com leite materno até 6 meses (MURAHOVSCHI e col. 1987) e com as curvas desenvolvidas pelo WHO Working Group on Infant Growth, que se referem a crianças de sete estudos realizados em paises afluentes (dois nos Estados Unidos, um na Dinamarca, um na Finlândia, um na Inglaterra, um no Canadá e um na Suécia - "12 months breast-pooled data set"). Estas crianças tiveram aleitamento materno exclusivo até pelo menos 4 meses e continuaram com leite materno até 12 meses ou mais (WHO 1994).

\section{b. Estudo da concentração de hemoglobina}

A Organização Mundial da Saúde estabelece critérios para diagnóstico de anemia para crianças somente a partir do $2^{\circ}$ semestre de vida. Propõe para 
crianças de 6 meses até 6 anos, $11 \mathrm{~g} / \mathrm{dL}$ como valor crítico de concentração de hemoglobina, abaixo do qual a criança é considerada anêmica (OMS 1975; DE MAEYER e col. 1989). Para menores de 6 meses ainda não existem valores mínimos padronizados para hemoglobina, abaixo dos quais o diagnóstico de anemia seja considerado positivo.

Encontramos trabalhos na literatura utilizando diferentes pontos de corte para diagnosticar a deficiência de ferro em crianças menores de 6 meses (ANDELMAN e SERED 1966; SAARINEN 1978; BRAULT-DUBUC e col. 1983; SICHIERI 1987; CALVO e col. 1992; MICHAELSEN e col. 1995; EMOND e col. 1996; DEWEY e col. 1998), o que impossibilita a comparação entre os mesmos, dificultando o estudo da situação do ferro e o diagnóstico da anemia nessas crianças.

Adotou-se para este estudo, 10,5 g/dL como valor mínimo esperado para a hemoglobina. Este valor foi o ponto mínimo encontrado por volta do segundo mês de vida, na curva de variação de hemoglobina do International Nutritional Anemia Consultative Group (INACG 1979). O uso de 10,5 g/dL como valor mínimo de hemoglobina foi sugerido por SIIMES e col. (1984) e tem sido utilizado para classificar como anêmicas crianças menores de 6 meses (SICHIERI 1987; MICHAELSEN e col. 1995).

Utilizou-se também para comparação, a curva de concentrações médias de hemoglobina do estudo de BRAULT-DUBUC e col.(1983), realizado com crianças canadenses sadias de zero a trinta e seis meses. 
4

RESULTADOS 


\section{RESULTADOS}

Estes resultados são referentes a uma amostra de 206 crianças alimentadas exclusivamente com leite materno, sendo $55,8 \%$ (115) do gênero masculino e $44,2 \%$ (91) do gênero feminino, com idades entre zero e seis meses (Tabela1).

Tabela 1 - Distribuição das crianças por sexo e idade. Centro de Lactação de Santos - SP, 1995/96.

\begin{tabular}{ccccccc}
\hline $\begin{array}{c}\text { Idade } \\
\text { (meses) }\end{array}$ & \multicolumn{2}{c}{ Masculino } & \multicolumn{2}{c}{ Feminino } & \multicolumn{2}{c}{ Total } \\
\hline 0 & $\mathrm{n}$ & $\%$ & $\mathrm{n}$ & $\%$ & $\mathrm{n}$ & $\%$ \\
\hline 1 & 37 & 62,7 & 22 & 37,3 & 59 & 100,0 \\
3 & 27 & 61,4 & 17 & 38,6 & 44 & 100,0 \\
6 & 26 & 56,5 & 20 & 43,5 & 46 & 100,0 \\
\hline \hline & 25 & 43,9 & 32 & 56,1 & 57 & 100,0 \\
\hline Total & 115 & 55,8 & 91 & 44,2 & 206 & 100,0 \\
\hline \hline
\end{tabular}

Para atingir nossos objetivos seria recomendado um estudo longitudinal, com o acompanhamento de uma coorte única desde o nascimento, como referido por diversos pesquisadores da área de Nutrição (ROCHE e HIMES 1980; OMS 1983; WHO 1986; HARISSON 1987). Entretanto, dificuldades de ordem prática e recursos financeiros necessários têm sido apontados como alguns dos fatores que contribuem para a escassez deste tipo de 
estudo (CARVALHAES 1988). Particularmente neste trabalho, duas dificuldades básicas impediram a utilização desse tipo de estudo. A primeira foi o seguimento de crianças em aleitamento materno exclusivo, limitado já no início do desenvolvimento deste estudo pela instalação de grupos de incentivo ao aleitamento materno na maioria das Policlinicas de Saúde de Santos, obedecendo ao modelo do Centro de Lactação. Com isso, a demanda do Centro de Lactação de Santos, já restrita às mulheres que utilizavam a maternidade do Hospital Guilherme Álvaro, ficou diminuída, visto que as mesmas procuravam o serviço de puericultura mais conveniente. A segunda dificuldade foi a colheita de mais de uma amostra de sangue de cada criança.

A média de peso ao nascer das crianças foi de $3,365 \mathrm{Kg}$ (desvio padrão $=$ 0,42). Não foi encontrada diferença estatisticamente significante entre as médias dos pesos de nascimento das crianças dos diferentes grupos de idade estudados $(p>0,05)$, como mostra a Tabela 2 . 
Tabela 2 - Média e desvio padrão do peso ao nascer por idade. Centro de Lactação de Santos - SP, 1995/96.

\begin{tabular}{cccc}
\hline $\begin{array}{c}\text { Idade } \\
\text { (meses) }\end{array}$ & $\mathrm{n}^{*}$ & $\begin{array}{c}\text { Média } \\
(\mathrm{Kg})\end{array}$ & Desvio Padrão \\
\hline 0 & 59 & 3,372 & 0,400 \\
1 & 42 & 3,335 & 0,390 \\
3 & 41 & 3,391 & 0,450 \\
6 & 46 & 3,361 & 0,450 \\
\hline \hline
\end{tabular}

^Perda: 18 crianças que não tinham este dado registrado no prontuário.

DEWEY e col. (1992b), comparando o crescimento de crianças amamentadas de uma população americana afluente com o de uma população pobre de Huascar no Peru, encontraram médias de peso de $3,611 \mathrm{Kg}$ e 3,316 Kg, respectivamente. Observa-se semelhança nas médias de peso entre crianças nascidas no Peru e as deste estudo.

$\mathrm{Na}$ distribuição das crianças segundo peso ao nascer nota-se $18,6 \%$ de crianças com peso abaixo de $3,000 \mathrm{Kg}$ (Tabela 3 ). 
Tabela 3 - Distribuição das crianças segundo o peso ao nascer. Centro de Lactação de Santos - SP, 1995/96.

\begin{tabular}{ccc}
\hline $\begin{array}{c}\text { Peso ao nascer } \\
(\mathrm{Kg})\end{array}$ & $\mathrm{n}^{*}$ & $\%$ \\
\hline $2,600 \vdash 3,000$ & 35 & 18,6 \\
$3,000 \vdash 3,500$ & 85 & 45,2 \\
$3,500 \vdash 4,000$ & 56 & 29,8 \\
$4,000 \mathrm{e}+$ & 12 & 6,4 \\
\hline \hline Total & 188 & 100,00 \\
\hline \hline
\end{tabular}

Obs: "Perda: 18 crianças que não tinham este dado registrado no prontuário.

Embora o comprimento das crianças não fosse objeto deste estudo, verificou-se que o comprimento médio ao nascer foi de $49,44 \mathrm{~cm}$ (desvio padrão $=2,03$ ) e que não houve diferença significante no comprimento ao nascer das crianças dos diferentes grupos etários.

Os valores encontrados mostraram que as medidas de peso e comprimento ao nascer foram semelhantes nos grupos de crianças estudadas, o que permite supor, que a evolução das mesmas seguirá igual modelo, uma vez que a alimentação de todas foi comum e única. 


\subsection{Crescimento}

$\mathrm{Na}$ Figura 1 observa-se a distribuição dos valores de escore $Z$ do peso para idade $(\mathrm{P} / \mathrm{l})$ do conjunto das crianças. Nota-se que a curva assemelha-se à da população de referência (NCHS).

Figura 1 - Distribuição do índice escore-z (peso/idade) de crianças de 0 a 6 meses de idade. Centro de Lactação de Santos. SP. $1995 / 96$.

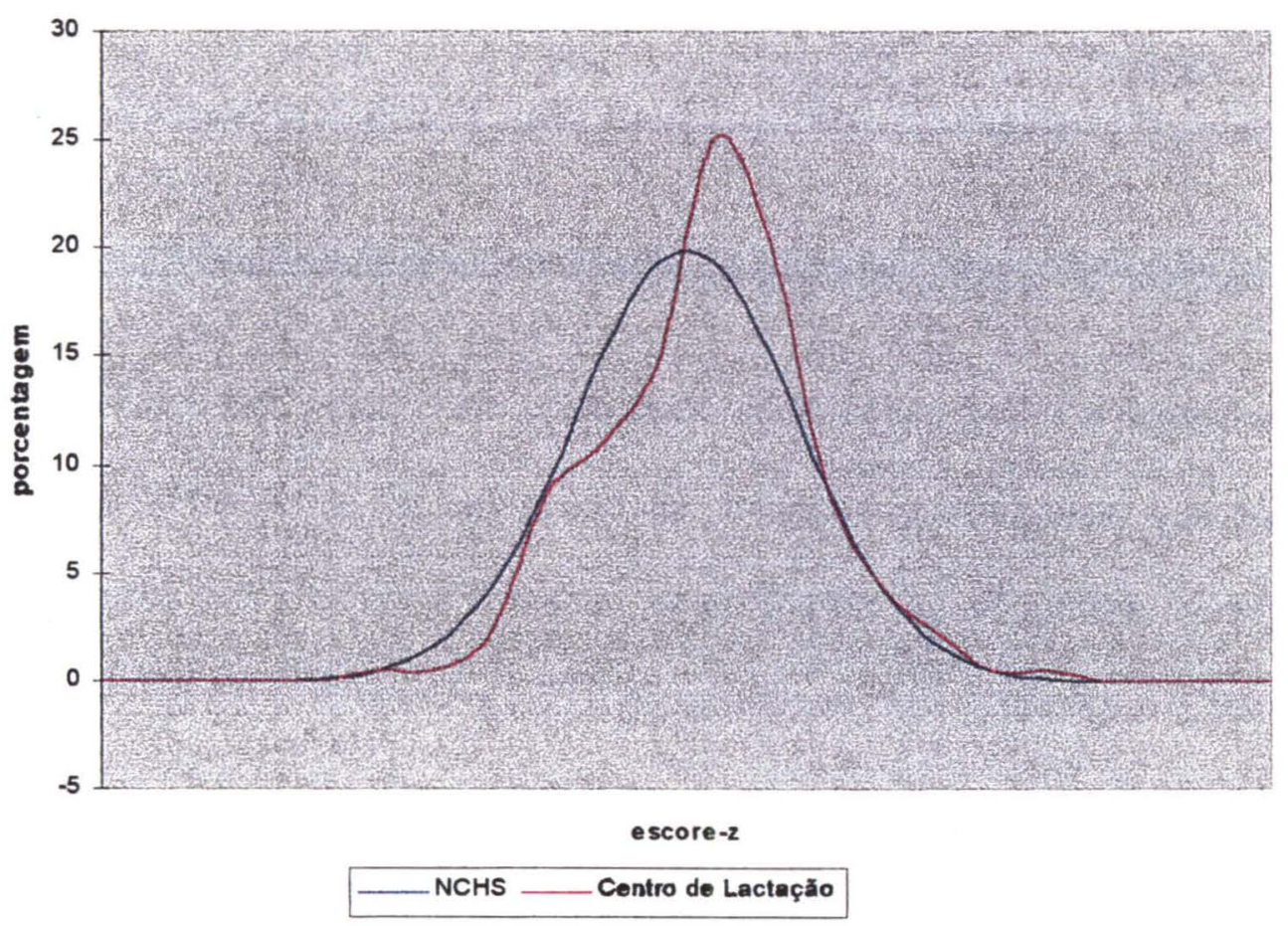

A Tabela 4 apresenta a média e mediana de peso das crianças nas diferentes idades no momento da colheita de sangue. Como pode ser observado essas distribuições são semelhantes àquela do NCHS. 
Tabela 4 - Média e mediana de peso no momento da colheita do sangue. Centro de Lactação de Santos - SP, 1995/96.

\begin{tabular}{lcccc}
\hline Idade & \multicolumn{3}{c}{ Peso } & $\mathrm{NCHS}^{(1)}$ \\
& $\mathrm{n}^{*}$ & $\begin{array}{c}\text { média } \\
(\mathrm{Kg})\end{array}$ & $\begin{array}{c}\text { mediana } \\
(\mathrm{Kg})\end{array}$ & $(\mathrm{Kg})$ \\
\hline Recém-nascido & 59 & 3,372 & 3,370 & 3,250 \\
1 mês & 39 & 4,315 & 4,370 & 4,150 \\
3 meses & 37 & 5,917 & 5,830 & 5,700 \\
6 meses & 48 & 7,600 & 7,510 & 7,500 \\
\hline
\end{tabular}

(1) NCHS/WHO (1977).

(2) *Perda: 23 crianças que não tinham este dado registrado no prontuário.

HITCHCOCK e col. (1981), em um estudo prospectivo sobre o crescimento e práticas alimentares de um grupo de crianças australianas que foram amamentadas nos primeiros 6 meses, encontraram as seguintes medianas de peso: $6,050 \mathrm{Kg}$ (meninos) e $5,720 \mathrm{Kg}$ (meninas) aos 3 meses e 7,890 Kg (meninos) e 7,380 $\mathrm{Kg}$ (meninas) aos 6 meses. Registra-se que estas crianças eram de familias de renda alta, sendo que aos 3 meses, $20 \%$ já recebiam suco de frutas, cereais e pudins e que aos 6 meses a amamentação exclusiva era restrita a $8 \%$ delas.

A Tabela 5 apresenta a média de ganho de peso das crianças no decorrer do periodo estudado. O crescimento observado durante este período assemelha-se ao da população do NCHS. VICTORA e col. (1998b) em um estudo com crianças de uma área relativamente desenvolvida no sul do 
Brasil registraram ganhos de peso semelhantes aos encontrados neste estudo.

Tabela 5 - Média de ganho de peso no periodo estudado. Centro de Lactação de Santos - SP, 1995/96.

\begin{tabular}{llllc}
\hline Periodo & \multicolumn{2}{c}{$\begin{array}{c}\text { Ganho de Peso } \\
(\mathrm{Kg})\end{array}$} & $\begin{array}{c}\text { NCHSMHO } \\
(2)\end{array}$ \\
\hline 0 a 1 mês & 39 & 0,997 & $(0,495)$ & 0,900 \\
0 a 3 meses & 36 & 2,570 & $(0,742)$ & 2,450 \\
0 a 6 meses & 45 & 4,230 & $(0,936)$ & 4,250 \\
\hline
\end{tabular}

(1) média e Desvio-padrão

(2) NCHSMHO (1977).

Na Figura 2 pode ser observado o padrão de crescimento das crianças do Centro de Lactação de Santos, apresentado em escore $Z$ de peso para idade em relação ao padrão do NCHS. Apesar da curva ter mostrado um declínio a partir do terceiro mês, manteve-se acima da mediana do padrão durante todo o periodo. 
Figura 2 - Média de escore $Z$ (pesolidade) de crianças de 0 a 6 meses. Centro de Lactação de Santos - SP, 1995/96.

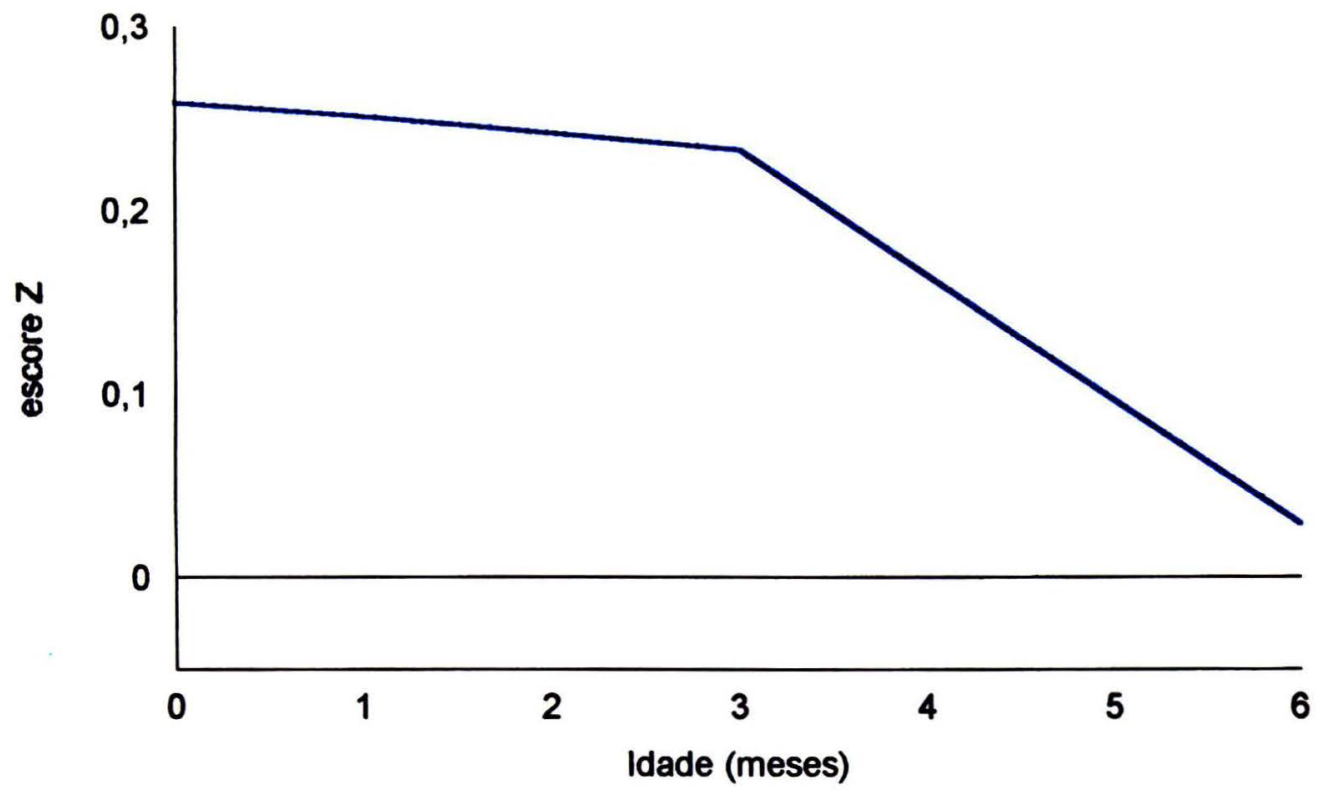

Fonte: NCHS - WHO (1977)

Ao examinar o padrão de crescimento de diferentes populações de crianças amamentadas que utilizaram o escore $Z$, tendo como referência o NCHS verifica-se uma tendência ascendente nas curvas de peso para idade (P/I) durante os primeiros 2 a 3 meses seguida por uma desaceleração. Nos países industrializados os valores médios de escore $Z$ de $P / l$ situavam-se acima da mediana NCHS (WHO 1994). Na amostra estudada não foi observada a tendência ascendente. As crianças tiveram um crescimento praticamente constante até o terceiro mês e depois um ligeiro declínio como pode ser observado na Figura 2. Os valores, apesar de positivos, estiveram bem próximos das médias do padrão. 
Existe um consenso a respeito da inadequação da utilização do padrão do NCHS para a avaliação do crescimento de crianças alimentadas com leite materno; no entanto, não existe ainda uma curva padrão de uso internacional para acompanhar o crescimento dessas crianças.

Dois estudos disponiveis na literatura, apresentam curvas de crescimento de crianças amamentadas. O primeiro foi elaborado com crianças do município de Santos - São Paulo, alimentadas exclusivamente com leite materno durante 0 primeiro semestre de vida e matriculadas na mesma instituição onde esta pesquisa foi desenvolvida (MURAHOVSCHI e col. 1987). O segundo, mais recente, é constituido por um conjunto de crianças de sete paises, todos desenvolvidos, que tiveram aleitamento materno exclusivo até pelo menos 4 meses e continuaram com leite materno até 12 meses ou mais (WHO 1994).

As Figuras $3 a$ e $3 b$ apresentam o crescimento dos meninos e meninas do Centro de Lactação comparado com o crescimento das crianças do estudo de MURAHOVSCHI e col. (1987). Pode ser observado que as curvas são semelhantes, sendo que a dos meninos está ligeiramente acima do padrão e a das meninas ligeiramente abaixo. 
Figura 3a - Comparação do peso médio para idade de meninos com aleitamento materno exclusivo. Centro de Lactação de Santos - SP. 1995/96.

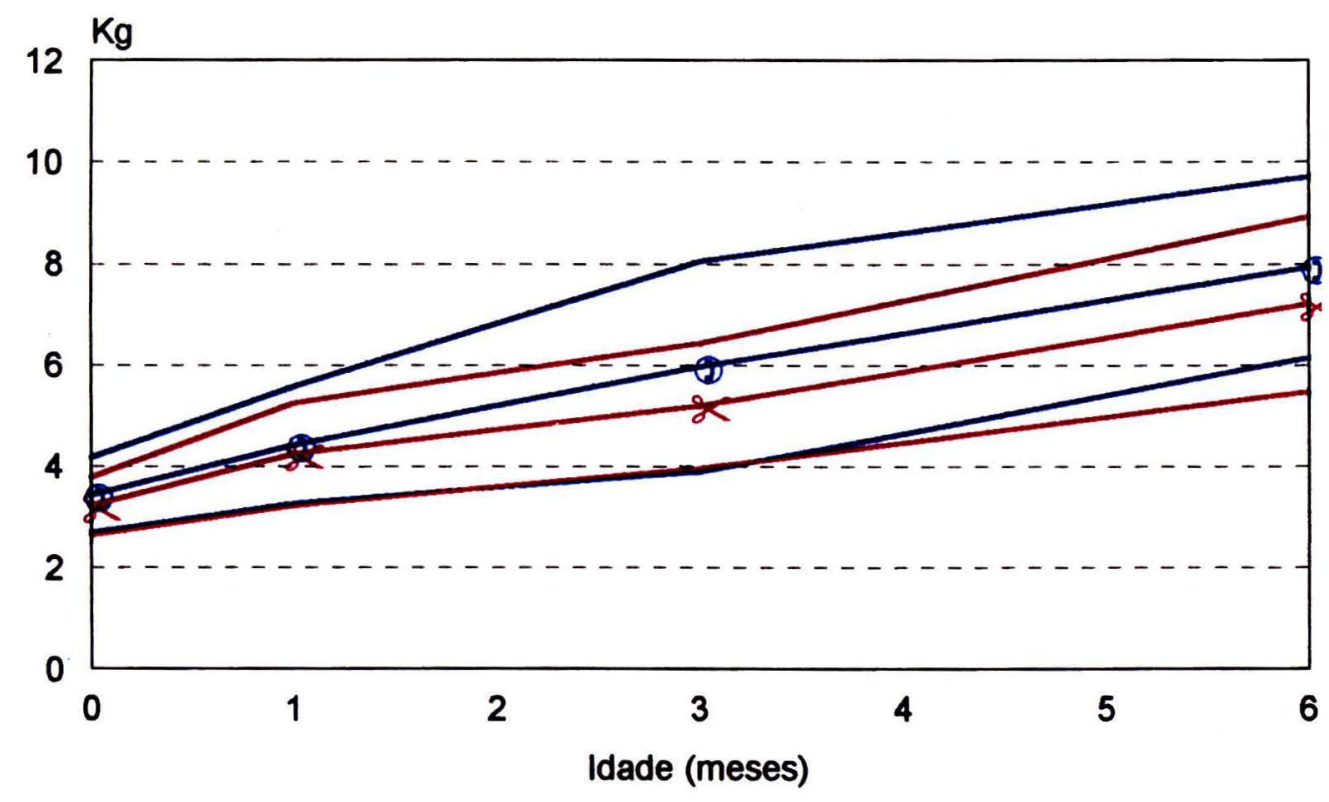

Figura 3b - Comparação do peso médio para idade de meninas com aleitamento materno exclusivo. Centro de Lactaçăo de Santos - SP. 1995/1996.

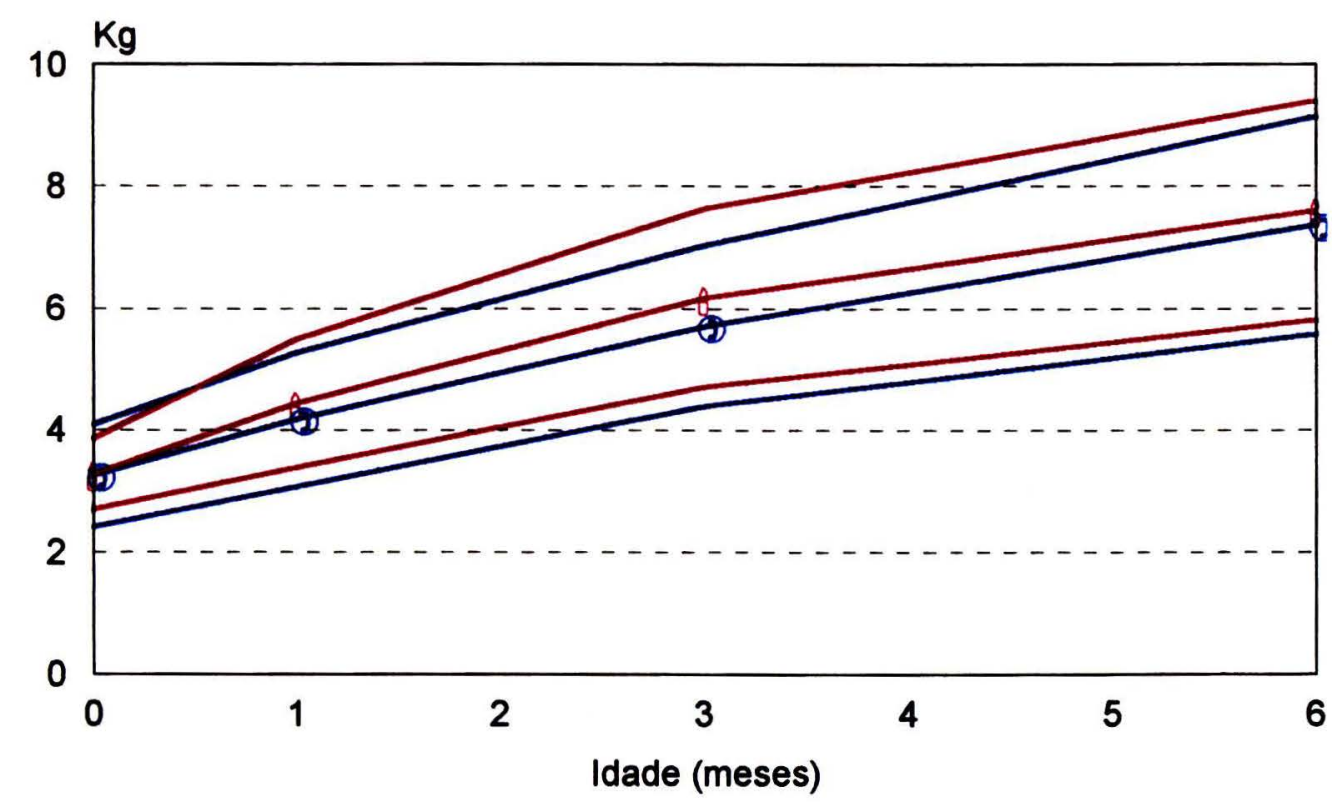

-- Centro de Lactação (+ -2 DP)

- Murahovschi e col. 1987 (+ -2DP) 
As Figuras $4 a$ e $4 b$ mostram que não houve diferença entre o crescimento dos meninos e das meninas do Centro de Lactação e do estudo da WHO (1994).

Figura 4a - Comparação do peso médio para idade de meninos com aleitamento materno. Centro de Lactaçăo de Santos - Sp. $1995 / 96$.

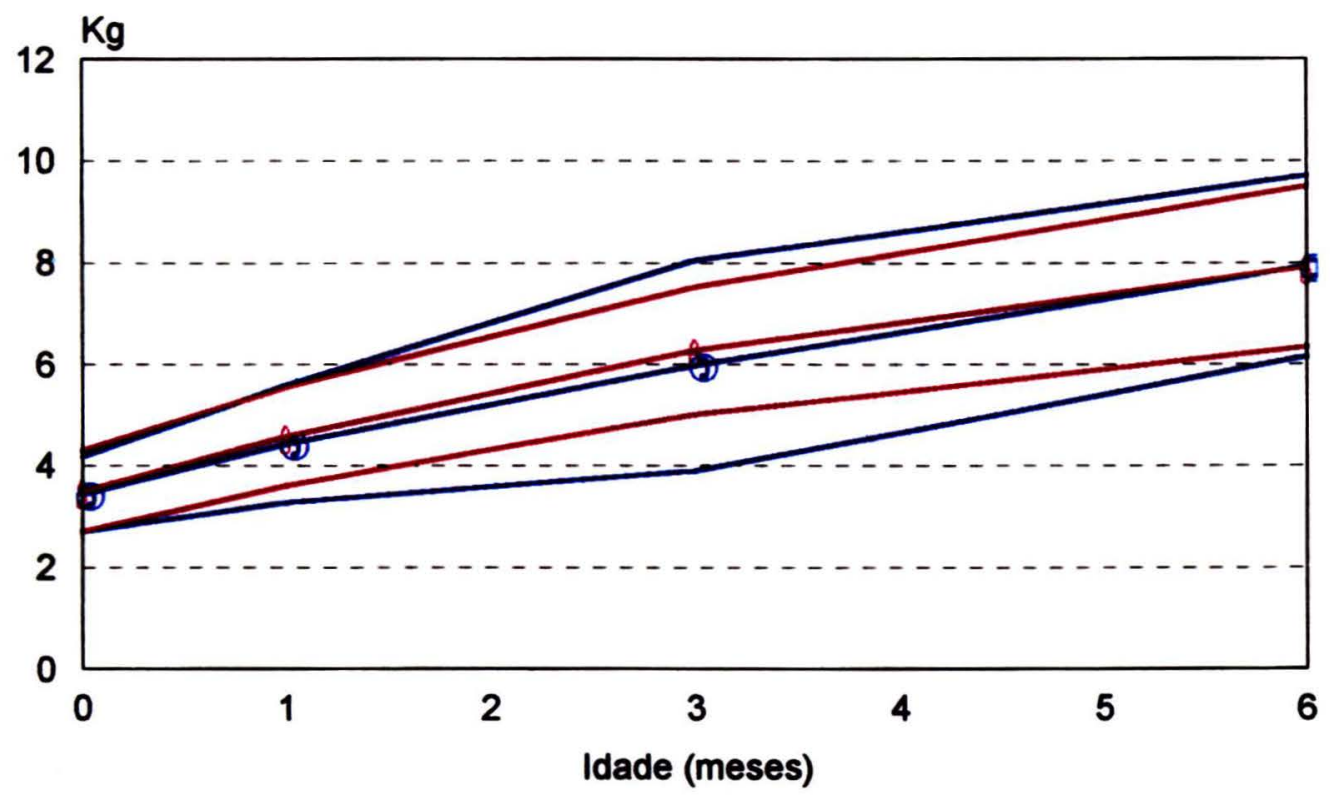

-- Centro de Lactação (+ -2 DP)

-- Breast-fed pooled data set, WHO - 1994 (+ -2 DP) 
Figura 4b - Comparação do peso médio para idade de meninas com aleitamento materno. Centro de Lactação de Santos - SP. $1995 / 96$.

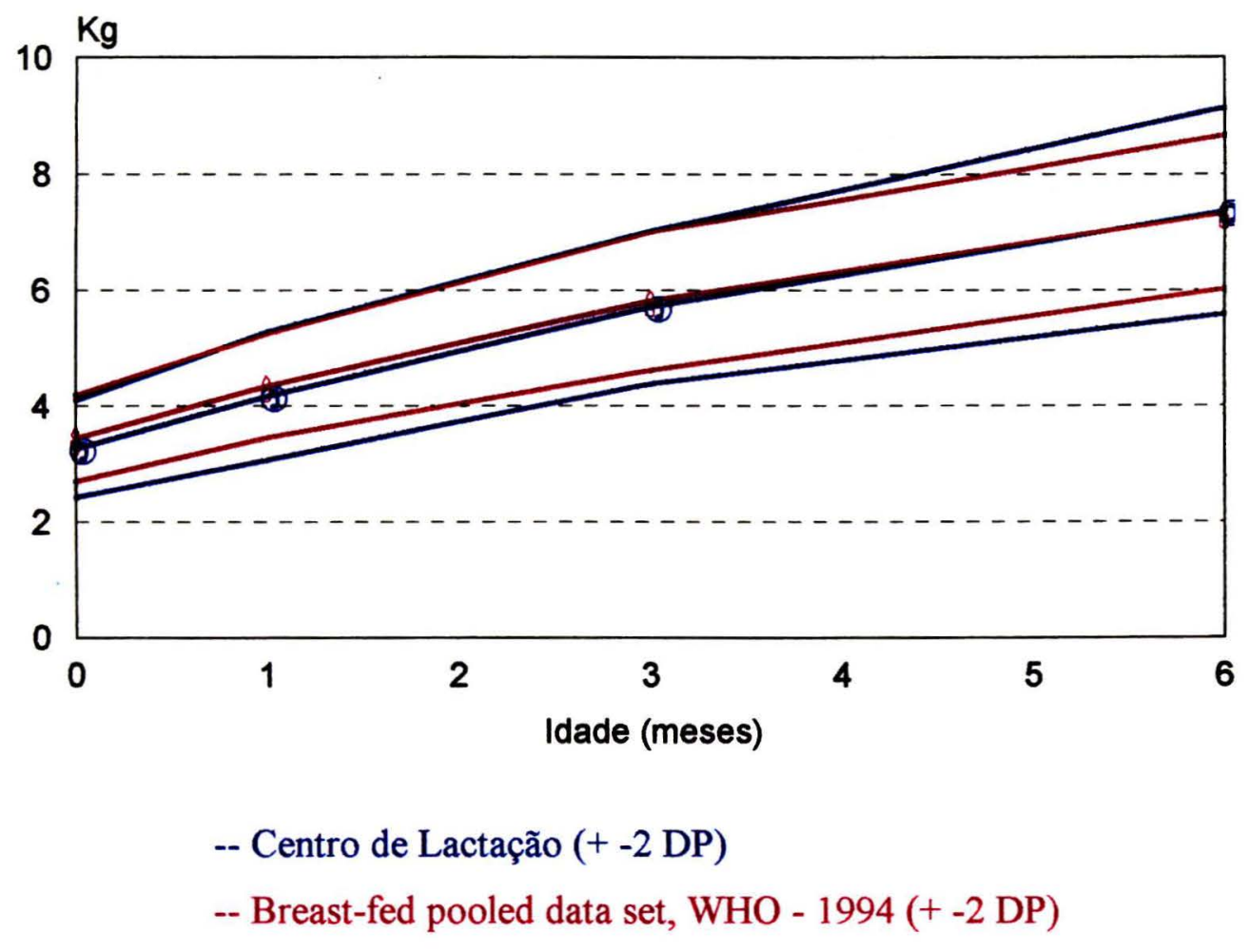

\subsection{Nivel de concentração de hemoglobina}

A medida de concentração de hemoglobina constitui a avaliação bioquímica mais comum da situação nutricional do ferro e apresenta as seguintes vantagens: fácil operacionalização, baixo custo, utilização internacional (INACG 1985), além de ser o indicador conceitual para diagnóstico da anemia.

A Tabela 6 apresenta os valores médios de concentração de hemoglobina das crianças estudadas, nas diferentes idades. 
Tabela 6 - Valores médios e desvios padrão da concentração de hemoglobina segundo a idade. Centro de Lactação de Santos - SP, 1995/1996.

\begin{tabular}{cccc}
\hline $\begin{array}{l}\text { Idade } \\
\text { (meses) }\end{array}$ & $n$ & $\begin{array}{c}\text { Concentração } \\
\text { de hemoglobina } \\
\bar{X}(\mathrm{~g} / \mathrm{dL})\end{array}$ & Desvio Padrão \\
\hline 0 & 59 & 15,6 & 1,6 \\
1 & 44 & 11,9 & 1,4 \\
3 & 46 & 10,0 & 0,8 \\
6 & 57 & 10,4 & 1,2 \\
\hline \hline & & 12,1 & 2,6 \\
\hline \hline
\end{tabular}

A Figura 5 compara as médias de concentração da hemoglobina das crianças atendidas no Centro de Lactação, com as médias do estudo longitudinal de BRAULT-DUBUC e col. (1983), realizado com 425 crianças canadenses de famílias de origem francesa e de nível sócioeconômico alto, que tiveram introdução precoce de cereais enriquecidos com ferro na dieta. Observa-se a mesma tendência entre as duas curvas, sendo que as crianças do Centro de Lactação apresentam sempre valores de hemoglobina mais baixos. A diferença entre esses valores foi significante (Teste $\mathrm{T}$ ao nivel de $5 \%$ de significância). Nota-se também, que o valor mais baixo de hemoglobina foi encontrado aos 3 meses nas duas populações, sendo $10,0 \mathrm{~g} / \mathrm{dL}$ nas crianças brasileiras e $11,3 \mathrm{~g} / \mathrm{dL}$ nas crianças canadenses. 
Figura 5 - Médias das concentrações de hemoglobina de crianças de 0 a 6 meses em aleitamento materno exclusivo. Centro de Lactaçăo de Santos - SP, 1995/96.

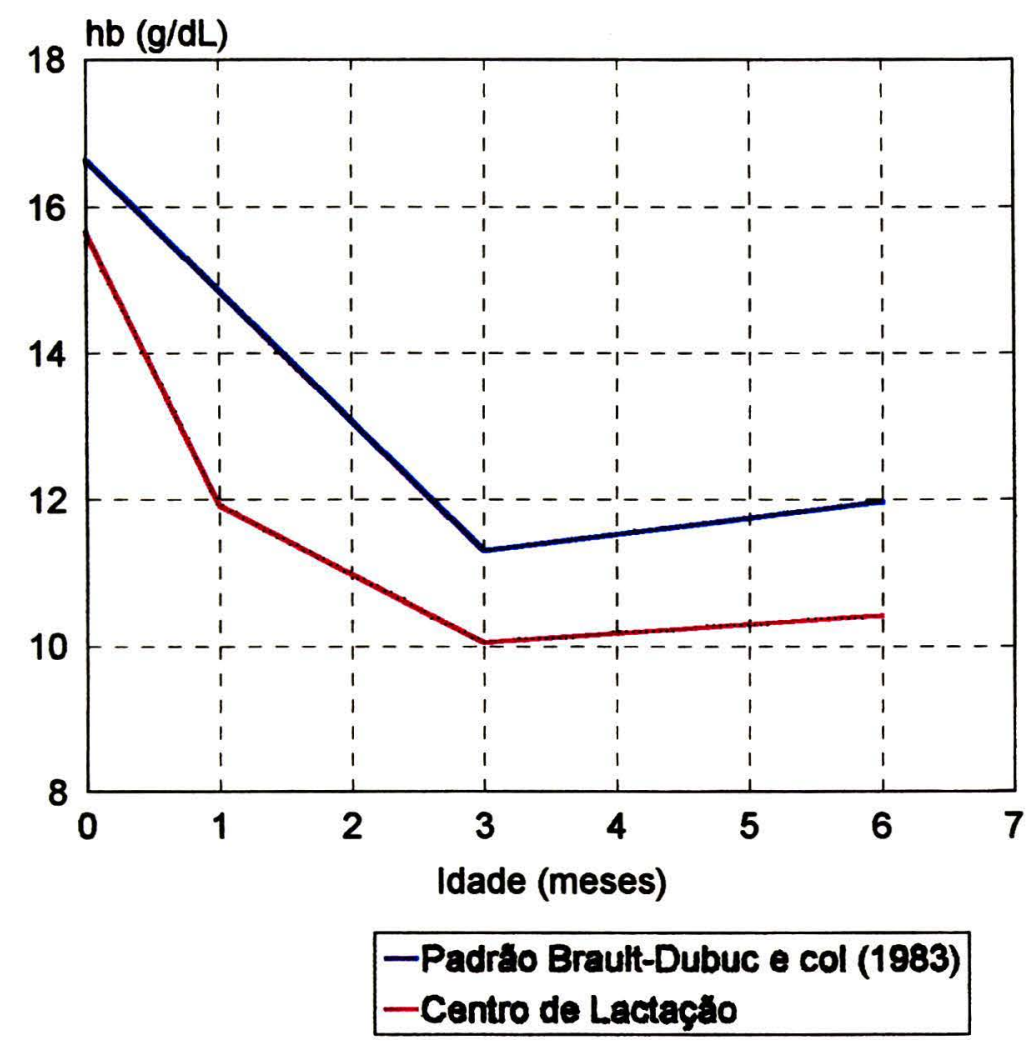

A Tabela 7 apresenta a distribuição das crianças segundo os valores de concentração de hemoglobina e a idade. Nota-se $45,2 \%$ de crianças com concentração de hemoglobina abaixo de $11,0 \mathrm{~g} / \mathrm{dL}$, sendo que destas, a grande maioria situa-se abaixo de $10,5 \mathrm{~g} / \mathrm{dL}$, valor adotado neste estudo como o mínimo esperado para a normalidade. 0 percentual antes referido foi maior do que o registrado por SICHIERI (1987), em crianças menores de 6 meses, no município de São Paulo $(31,1 \%)$. Observa-se a grande proporção de crianças de 3 e 6 meses com hemoglobina abaixo de 10,5 g/dL, que correspondeu a, respectivamente, $71,7 \%$ e 56,2\%, sugerindo a diminuição da 
sintese de hemoglobina adulta, o que geralmente resulta no desenvolvimento de anemia. Ressalta-se, no entanto, que o processo de transformação da hemoglobina fetal em hemoglobina adulta pode não ter se completado nos primeiros três meses de vida, explicando parte do elevado percentual encontrado $(71,7 \%)$.

Tabela 7 - Distribuição das crianças segundo a concentração de hemoglobina e idade. Centro de Lactação de Santos - SP, $1995 / 96$.

\begin{tabular}{|c|c|c|c|c|c|c|c|c|c|c|}
\hline \multirow{3}{*}{$\begin{array}{l}\text { Hemoglobina } \\
(\mathrm{g} / \mathrm{dL})\end{array}$} & & & \multicolumn{6}{|c|}{ Idade (meses) } & \multicolumn{2}{|c|}{ Total } \\
\hline & \multicolumn{2}{|c|}{0} & \multicolumn{2}{|r|}{1} & \multicolumn{2}{|c|}{3} & \multicolumn{2}{|c|}{6} & \multirow[b]{2}{*}{$n$} & \multirow[b]{2}{*}{$\%$} \\
\hline & $n$ & $\%$ & $n$ & $\%$ & $n$ & $\%$ & $n$ & $\%$ & & \\
\hline$<10,5$ & - & - & 6 & 13,6 & 33 & 71,7 & 32 & 56,2 & 71 & 34,5 \\
\hline $10,5 \vdash 11,0$ & - & - & 5 & 11,4 & 9 & 19,6 & 8 & 14,0 & 22 & 10,7 \\
\hline$\geq 11,0$ & 59 & 100,0 & 33 & 75,0 & 4 & 8,7 & 17 & 29,8 & 113 & 54,8 \\
\hline Total & 59 & 100,0 & 44 & 100,0 & 46 & 100,0 & 57 & 100,0 & 206 & 100,0 \\
\hline
\end{tabular}

A anemia é considerada rara em crianças menores de seis meses de vida (COMMITTEE ON NUTRITION 1976; MCMILLAN e col. 1976; AKRE 1989). Portanto, os resultados encontrados neste estudo, no qual é grande número de crianças com valores de hemoglobina abaixo do mínimo esperado, alertam para uma situação preocupante.

Analisamos dois fatores da maior relevância na determinação da anemia: o peso ao nascer e o crescimento. 
Considerando que durante a vida intra-uterina o feto acumula ferro em quantidade proporcional a seu aumento de peso ( WOODRUFF 1977; OSKI e NAIMAN 1984), foi realizada uma análise de correlação entre o nível de hemoglobina e do peso dos recém-nascidos. O resultado mostrou uma baixa correlação entre estas variáveis, contrariando a afirmação encontrada na literatura científica especializada (Figura 6).

Figura 6 - Correlação do peso ao nascer $(\mathrm{Kg})$ com a concentração de hemoglobina ( $\mathrm{g} / \mathrm{dL}$ ) de crianças recém-nascidas. Centro de Lactaçăo de Santos, SP. 1995/1996.

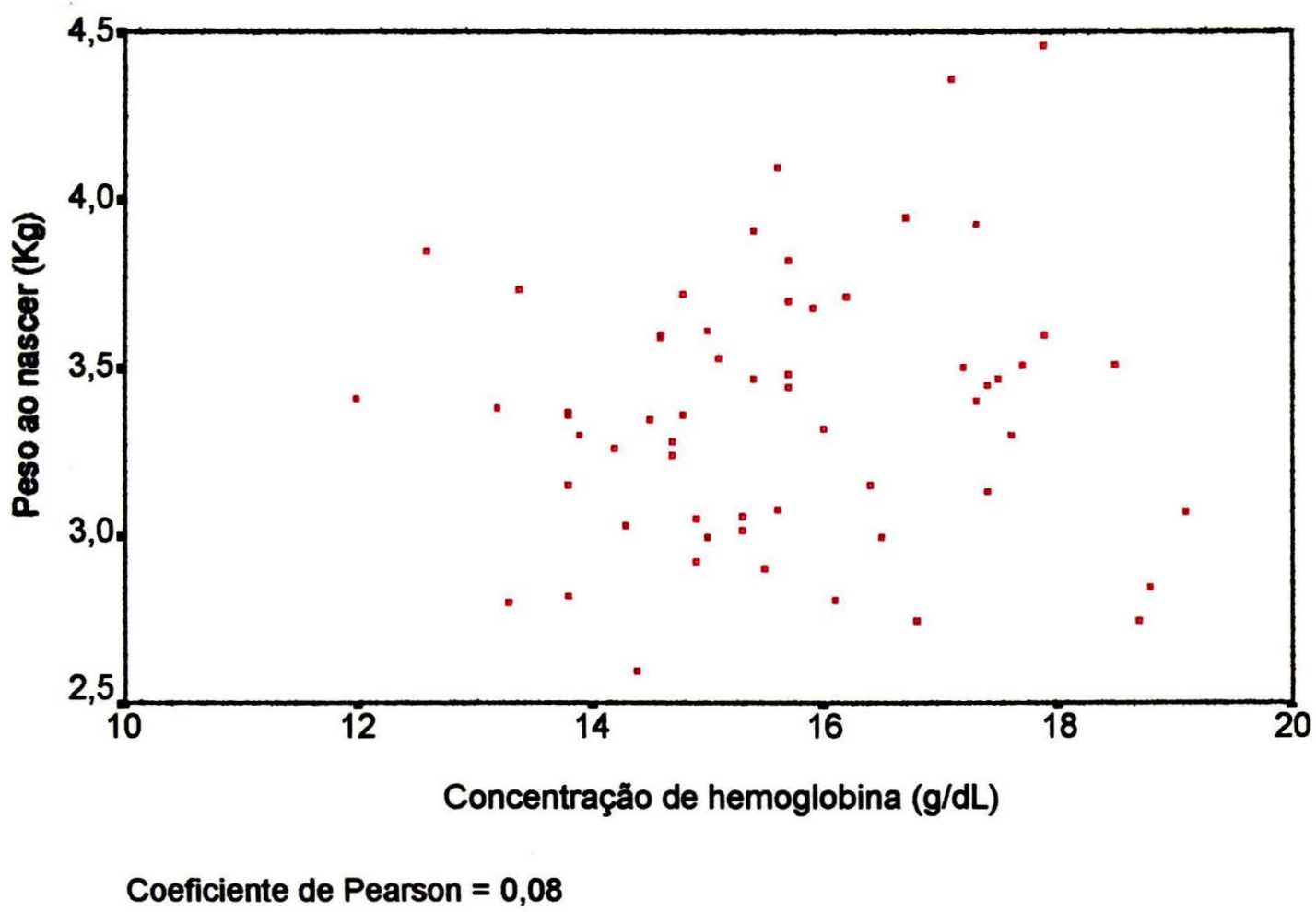

O peso ao nascer é fator importante para explicar o estado nutricional de ferro na infância. Num estudo sobre a anemia aos 6 meses em crianças amamentadas em Honduras, DEWEY e col. (1998) verificaram que o peso ao nascer estava fortemente relacionado com a concentração da hemoglobina 
naquele momento. Em nosso estudo, não encontramos nenhuma correlação do peso ao nascer com o nível de hemoglobina nas diferentes idades estudadas (Figura 7).

Figura 7 - Correlaçăo do peso ao nascer $(\mathrm{Kg})$ com a concentraçăo atual de hemoglobina $(\mathrm{g} / \mathrm{dL}$ ) de crianças de 0 a 6 meses. Centro de Lactaçăo de Santos, SP. 1995/96.

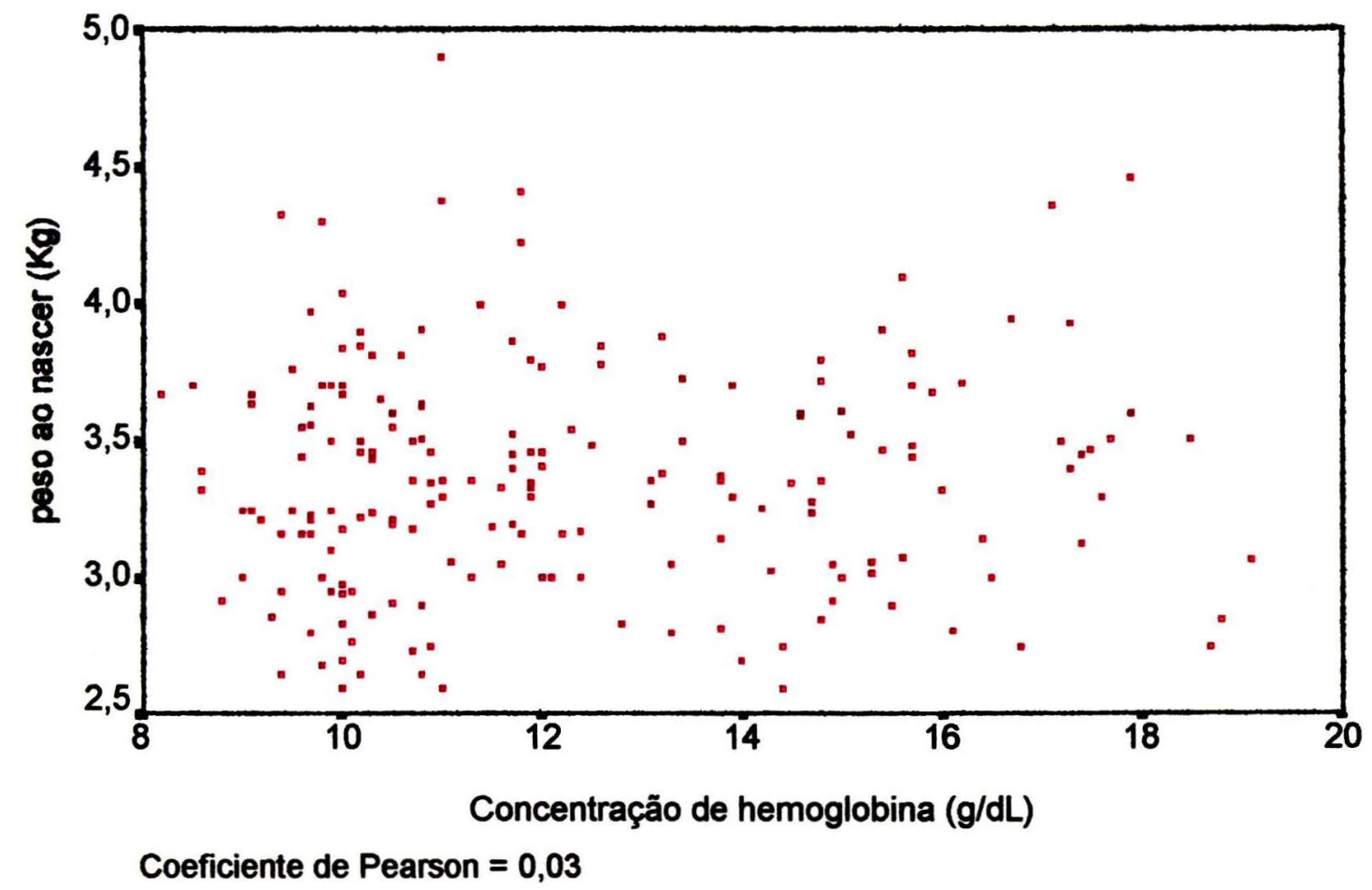

O crescimento acelerado é considerado o principal fator no desenvolvimento da deficiência de ferro nos primeiros meses de vida (INACG 1979).

Para verificar se a taxa de crescimento das crianças foi responsável pelos baixos valores de hemoglobina, procuramos relacionar o ganho de peso com o valor de concentração de hemoglobina. Entretanto, nenhuma correlação foi encontrada como pode ser observado na Figura 8. 
Figura 8 - Correlação de ganho de peso $(\mathrm{Kg})$ com a concentração atual de hemoglobina $(\mathrm{g} / \mathrm{dL})$ de crianças de 0 a 6 meses. Centro de Lactação de Santos, SP. 1995/1996.

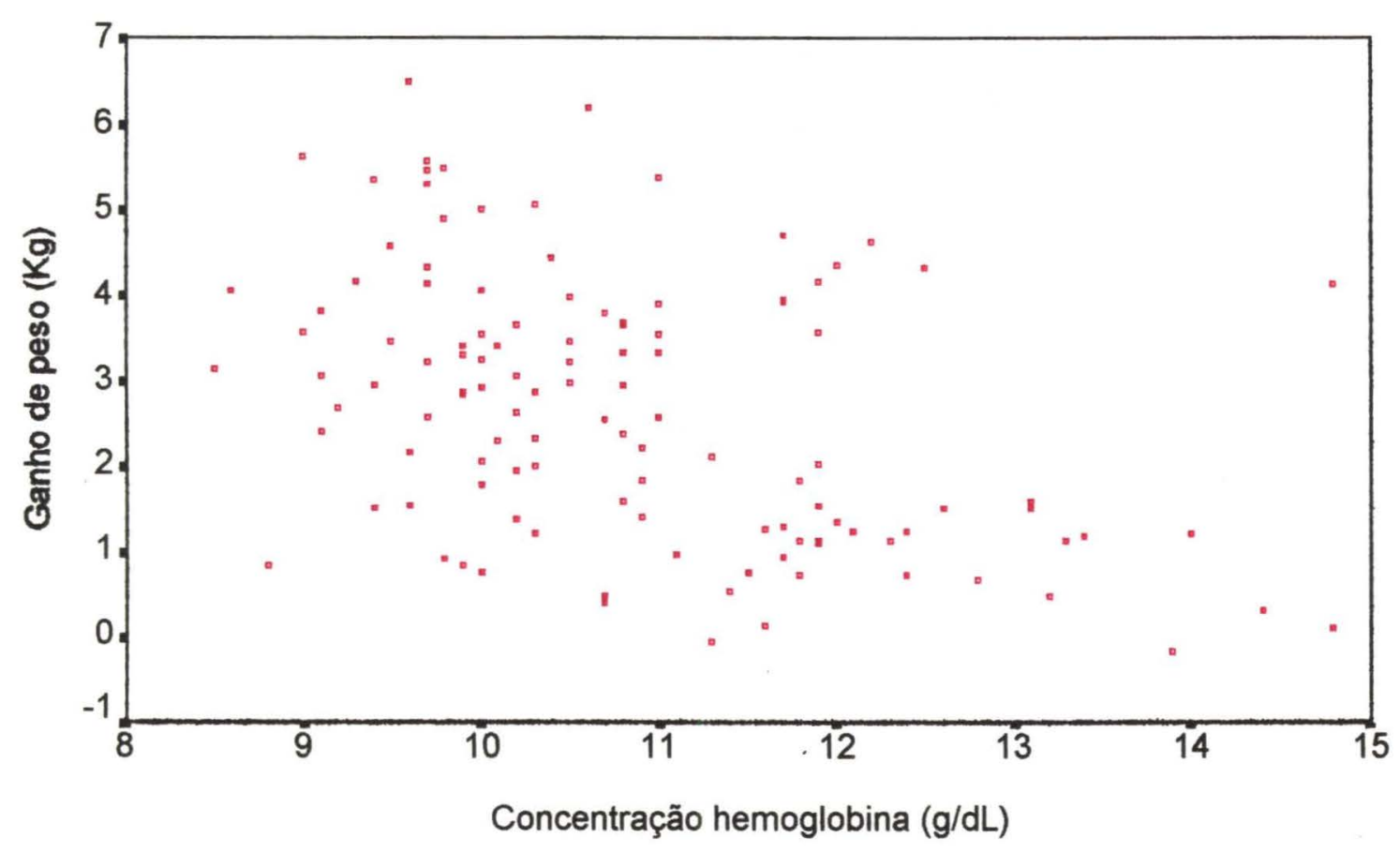

Coeficiente de Pearson $=-0,43$

Uma vez que a alimentação das crianças estudadas era comum e única, a influência do crescimento sobre a concentração de hemoglobina pode ser analisada sem que a dieta seja uma variável de confusão. Isto nos permite a realização de um cálculo teórico da concentração de hemoglobina, já realizado anteriormente por SICHIERI (1987) num estudo entre crianças do município de São Paulo. Para tal foi considerado que à quantidade de ferro veiculada pelo leite materno é inexpressiva em relação à quantidade endógena existente no nascimento. De acordo com o INACG (1979) o recém-nascido tem $75 \mathrm{mg}$ ferro / $\mathrm{Kg}$ de peso, $85 \%$ dos quais estão sob a 
forma de hemoglobina. Este ferro é redistribuido à medida que a criança cresce, porém a quantidade deste mineral é mantida constante. Uma vez que o volume sangüíneo corresponde a $85 \mathrm{~mL} / \mathrm{Kg}$ de peso (BRANDALISE e MATSUDA 1981) e que cada grama de hemoglobina contém $3,4 \mathrm{mg}$ de ferro (WHITE e col. 1976) tem-se a equação:

$\mathrm{Hb}$ estimada $=\frac{\mathrm{PN} \times 75 \times 0,85 \times 100}{3,4 \times \mathrm{PA} \times 85} \mathrm{~g} / \mathrm{dL}$

$\mathrm{Hb}$ - hemoglobina

$\mathrm{PN}$ - peso ao nascer em $\mathrm{Kg}$

$\mathrm{PA}$ - peso atual em $\mathrm{Kg}$

Usando a equação acima foi construída a Tabela 8 que apresenta os valores de hemoglobina medidos e estimados, distribuídos segundo o diagnóstico de anemia. Analisando estes valores, encontramos 35 crianças $(29,2 \%)$ com a hemoglobina real (medida) menor do que a estimada. Observa-se ainda nesta Tabela que, das crianças com valores mensurados menor que 10,5 $\mathrm{g} / \mathrm{dL}, 62,5 \%$ apresentam valor de hemoglobina estimada acima ou igual a este nivel, o que sugere um déficit de ferro. 
Tabela 8 - Distribuição das crianças segundo a concentração estimada de hemoglobina e a concentração medida, em g/dL. Centro de Lactação de Santos - SP, 1995/96.

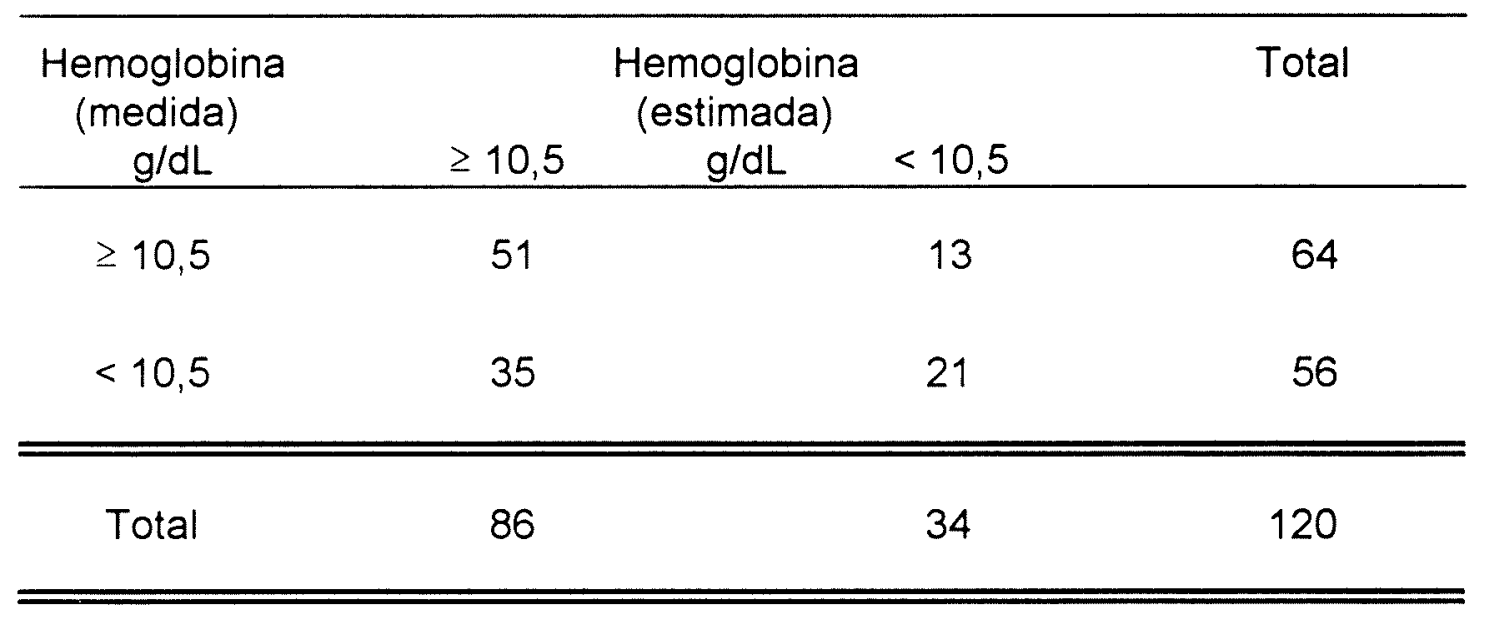

Fonte: Baseado em SICHIERI 1987.

$x^{2}=4,15$

O valor do qui-quadrado encontrado mostra uma associação entre as concentrações de hemoglobinas medidas e estimadas $\left(x^{2}=4,15\right)$.

Verificamos que não houve diferença entre as médias de incrementos de escore $Z$ de peso para idade das crianças com balanço negativo e positivo de ferro. $O$ pequeno número de crianças não permite fazer afirmações seguras. Porém, foi observado nas crianças que apresentaram balanço negativo de ferro (média de incremento de escore $Z$ igual a -0,42) uma tendência de crescimento inferior ao das crianças com balanço positivo (média de incremento de escore $Z$ igual a 0,06). 


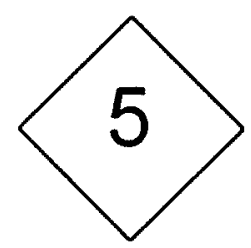

DISCUSSÃO 


\section{DISCUSSÃO}

A importância do aleitamento materno exclusivo durante os primeiros meses de vida na prevenção da mortalidade e morbidade está demonstrada em diversos estudos epidemiológicos. Este fato tem contribuido para que as agências internacionais enfatizem esta prática até os quatro a seis meses de vida em paises como o Brasil, onde boa parcela da população vive em condições precárias e a diarréia é apontada como segunda causa da mortalidade infantil.

É consenso que o aleitamento materno exclusivo é o método de alimentação ideal para a criança, enquanto for mantido um crescimento adequado. Entretanto, o critério de normalidade de crescimento está sujeito a diferentes interpretações e depende muito de uma referência apropriada. $\mathrm{Na}$ avaliação do crescimento de crianças amamentadas exclusivamente ao seio, o pesquisador depara-se com a falta de um padrão que permita comparações aceitas internacionalmente.

Esforços de técnicos da área da saúde de muitos países, conduzidos sob o apoio da OMS, estão sendo direcionados para a construção de um padrão internacional de crescimento. A principal razão para todo este esforço é a preocupação de que as curvas existentes não refletem o crescimento normal quando a alimentação é restrita ao leite de peito. $O$ uso destas curvas pode conduzir a decisões errôneas para complementar ou mesmo interromper o aleitamento materno. As inúmeras vantagens reconhecidas do aleitamento materno exclusivo confirmam que estas decisões seriam 
catastróficas, principalmente para as crianças dos paises em desenvolvimento.

Muito já se conhece a respeito da adequação do leite materno e crescimento. Alguns pesquisadores chegam a afirmar que a proteção que o leite materno confere à criança é superior ao fato delas crescerem menos que as crianças alimentadas com fórmulas.

O crescimento das crianças do Centro de Lactação de Santos, avaliado de acordo com o padrão do NCHS foi adequado. MURAHOVSCHI e col. já haviam encontrado nesta instituição resultado semelhante a este em 1987, quando construiram as curvas de crescimento de lactentes menores de seis meses aleitados exclusivamente ao seio.

Outros estudos apontaram o mesmo resultado durante os primeiros 4 meses (WHITEHEAD e PAUL 1981; DIAZ e col. 1995). BUTTE e col. (1984) registraram um crescimento satisfatório em crianças americanas quando comparadas com o padrão NCHS, apesar do consumo de energia e proteína ser menor que o recomendado.

A utilização da curva de crescimento do NCHS como padrão de referência é considerada inadequada por diversos investigadores, uma vez que foi construida com crianças cuja alimentação não era restrita ao leite materno. Em geral as crianças amamentadas que têm seu crescimento avaliado com este padrão, mesmo nos paises desenvolvidos, mostram uma diminuição no escore $Z$ do índice de peso/idade a partir do terceiro mês, característica que se mantem até o final do primeiro ano de vida. Esta inadequação também 
ocorre com o índice comprimento / idade, porém com uma diminuição menos acentuada. SEWARD e SERDULA (1984) mostraram numa revisão de alguns estudos disponíveis sobre o crescimento de crianças amamentadas exclusivamente ao seio, que a interpretação desse fenômeno não é unânime: para alguns representa uma insuficiência de crescimento, para outros é normal e as curvas é que não são adequadas.

Os pesquisadores da OMS (WHO 1994), ao avaliar o crescimento de crianças do Peru e da Índia, observaram que quando o padrão utilizado foi o NCHS, o declinio na curva de P/l ocorreu aos 3 meses; mas quando o padrão era constituído por crianças amamentadas, este declínio não ocorreu antes dos 5 meses.

Segundo WHITEHEAD e PAUL (1984) estes desvios têm importância ímpar quando os padrões de crescimento são utilizados para identificar o começo da inadequação da lactação e a necessidade de introduzir outros alimentos. Vieses na interpretação do crescimento de crianças amamentadas avaliadas com o padrão do NCHS levam não só as mães, como os pediatras a interromperem o aleitamento materno exclusivo. Isto é particularmente prejudicial para as crianças dos países em desenvolvimento, onde os riscos, associados com a introdução precoce de alimentos em condições sanitárias desfavoráveis, são bastante elevados (DEWEY e col. 1992b).

A proteção atribuida ao leite materno contra doenças é mais evidente nos primeiros 6 meses (VICTORA e col. 1987; BROWN e col. 1989). A recomendação para que seja dado a criança exclusivamente leite materno 
durante este periodo, deve-se principalmente ao fato de que o efeito protetor contra a diarréia possa diminuir substancialmente quando a criança receber além do leite materno qualquer outro alimento, inclusive água ou chá (BROWN e col. 1989; VICTORA e col. 1989; POPKIN e col. 1990). Registra-se também que a ingestão de outros alimentos pode interferir na biodisponibilidade de nutrientes essenciais existentes no leite materno, como está comprovado para o ferro e o zinco (SAARINEN e SIIMES 1979; OSKI e LANDAW 1980).

UNDERWOOD e HOFVANDER (1982), em um levantamento exaustivo para a OMS, apontam com detalhe os prós e os contras da introdução precoce de alimentos complementares. Seus argumentos contra essa prática são: o maior risco à infecção; a possibilidade de que o menor número de mamadas reduza a produção do leite materno e portanto, leve a uma maior demanda de alimentos complementares, e a possibilidade de que estes alimentos retardem a maturação do intestino, que é estimulada pelo consumo do leite materno, e que tem um significado importante para o desenvolvimento da função imunitária e para a prevenção da entrada de substâncias que provocam alergia. A única vantagem apontada pelos autores diz respeito à prevenção da alteração do crescimento.

Ao redor dos quatro a seis meses a criança encontra-se num estágio de maturação fisiológica que a torna capaz de aproveitar outros alimentos diferentes do leite materno. A OMS recomenda que os alimentos complementares sejam oferecidos à criança a partir destas idades (WHO 
1995). GIUGLIANI e VICTORA (1997) afirmam que as justificativas para essa recomendação se devem às variações da velocidade de crescimento de crianças nas diferentes regiões do mundo.

A avaliação do crescimento das crianças estudadas usando os dois padrões disponiveis construidos com crianças alimentadas exclusivamente com leite materno até 4 meses (WHO 1994) e até 6 meses (MURAHOVSCHI e col. 1987) confirmou o crescimento adequado das nossas crianças. Os pesquisadores da WHO (1994), responsáveis pelo estudo do "12 month breast-fed pooled data set", sugerem o uso destas curvas para a avaliação do crescimento de crianças em aleitamento materno, enquanto não houver um padrão internacional disponivel.

Quando se avalia a adequação do crescimento de crianças amamentadas, a técnica da amamentação deve ser considerada. Segundo GIUGLIANI e VICTORA (1997), a criança que não abocanha corretamente a mama, isto é, $2 \mathrm{~cm}$ do tecido mamário além da zona correspondente ao mamilo, pode apresentar déficit de ganho de peso por não conseguir ingerir o chamado leite posterior, mais nutritivo e rico em gorduras. Os autores afirmam que a correção da técnica da amamentação garante à criança um crescimento adequado, evitando a introdução precoce de alimentos. Esta afirmação é confirmada neste estudo, no qual o crescimento foi adequado com qualquer dos padrões utilizados. Ressalta-se que as mães eram orientadas para amamentar corretamente os seus filhos e isto era observado em todos os retornos. Este fato reforça a importância da alimentação ao seio correta e a 
necessidade da criação de mais centros de lactação, onde a orientação às mães é considerada fator primordial para o sucesso da amamentação.

MURAHOVSCHI e col. (1987) mostraram ainda que se a técnica da amamentação for correta, o crescimento das crianças em aleitamento materno exclusivo nos primeiros seis meses não depende de sua condição social.

COHEN e col. (1994) num estudo realizado em Honduras concluiram que o aleitamento materno exclusivo até os 6 meses pode ser recomendado mesmo em populações de baixo nível sócioeconômico; entretanto, os autores chamam a atenção para a adequação dos micronutrientes dessas crianças.

Relatos que apontam os riscos e benefícios da introdução de alimentos complementares são encontrados com freqüência na literatura. Mesmo nos países industrializados, no que diz respeito ao crescimento, as evidências indicam que não existe benefício na introdução de outros alimentos antes dos 6 meses. Entretanto, não se tem a mesma certeza sobre os efeitos do estado nutricional referente aos micronutrientes, particularmente, o ferro (DEWEY e col. 1998).

Sabe-se que as reservas de ferro neonatal esgotam-se em crianças nascidas a termo ao redor do $4^{\circ}$ mês, quando deve ser garantido um adequado fornecimento de ferro. É neste momento que a criança deve ter não só o seu crescimento avaliado como também as suas reservas de ferro. Destacamos para tanto a necessidade de um padrão que avalie os niveis de 
concentração de hemoglobina e pontos de corte que identifiquem a presença de anemia em crianças menores de seis meses.

A anemia nutricional por deficiência de ferro é apontada hoje como a doença carencial de maior prevalência na população infantil em nosso meio. A utilização do nivel de concentração de hemoglobina para o diagnóstico de anemia ferropriva, mesmo na ausência de outros exames bioquímicos, é considerada adequada em populações onde a deficiência de ferro apresenta alta prevalência (INACG 1977; DALLMAN e REEVES 1984). Os estudos realizados em São Paulo nos últimos anos registraram o aumento dessa prevalência, principalmente entre as crianças menores de 1 ano (SIGULEM e col. 1978; MONTEIRO e SZARFARC 1987; TORRES e col. 1994a).

Até o momento, nenhum critério foi estabelecido para diagnosticar anemia no primeiro semestre de vida. A fixação de um valor de hemoglobina como ponto de corte de normalidade em crianças menores de 6 meses é muito difícil. Ao nascer, a hemoglobina apresenta seu valor mais alto, situado ao redor de 18,0 g/dL (DALLMAN e col. 1980; MONZON 1985); ocorre depois uma rápida queda, atingindo o mais baixo nivel entre a $8^{\mathrm{a}}$ e $12^{\mathrm{a}}$ semana de vida (TRICTA JUNIOR 1986). Este declínio é considerado normal e acontece sem que as reservas de ferro estejam esgotadas. A partir daí, esse processo é revertido, chegando a um valor médio de $12,5 \mathrm{~g} / \mathrm{dL}$ aos 6 meses, que é mantido durante o restante do primeiro ano (DALLMAN e col. 1980; MONZON 1985). 
Os estudos realizados por SAARINEN e SIIMES (1978) e INACG (1979) registraram o valor mínimo de hemoglobina de $11,2 \mathrm{~g} / \mathrm{dL}$ e $10,5 \mathrm{~g} / \mathrm{dL}$, respectativamente, ao redor do $2^{\circ}$ mês de vida. Neste estudo, o valor mínimo $10,0 \mathrm{~g} / \mathrm{dL}$ foi encontrado ao redor do $3^{\circ}$ mês.

OSKI (1975) afirma que pouco se conhece sobre a ocorrência da deficiência de ferro no início da vida e que não está claro, principalmente, como a reserva de ferro neonatal afeta a subsequente reserva na infância.

Alguns pesquisadores têm chamado a atenção para a presença de valores baixos de hemoglobina entre crianças menores de 6 meses, mesmo sem um padrão internacional que estabeleça um limite mínimo, abaixo do qual a criança é diagnosticada como anêmica.

O conjunto de crianças estudadas apresentou ao nascer um nível médio de hemoglobina de 15,6 g/dL. Este valor foi semelhante ao encontrado por SZARFARC em São Paulo (1972) em recém-nascidos de baixo nível sócioeconômico e por BRATLID e MOE (1980) em uma região periférica da cidade de Oslo na Noruega. Deve ser realçado que este valor situa-se abaixo daquele utilizado habitualmente como referência $(18,0 \mathrm{~g} / \mathrm{dL})$.

MOLLISON e CUTBUSH (1951) propuseram como valor mínimo para hemoglobina ao nascer, $13,6 \mathrm{~g} / \mathrm{dL}$. Considerando este valor, verificamos a presença de $8,5 \%$ de recém-nascidos anêmicos na maternidade do Hospital Guilherme Álvaro. SZARFARC (1972) encontrou no estudo antes citado, 21\%. ARRUDA (1998) num levantamento realizado com recém-nascidos do 
Instituto Materno Infantil de Pernambuco encontrou $23,7 \%$ de crianças com hemoglobina ao nascer, abaixo deste valor.

Os demais valores da hemoglobina observados no $1^{\circ}, 3^{\circ}$ e $6^{\circ}$ mês, estiveram sempre abaixo daqueles referidos por BRAULT-DUBUC e col. (1983) no estudo com crianças canadenses. Deve ser registrado, entretanto, que além da diferença sócioeconômica, as crianças do Centro de Lactação foram alimentadas somente com leite materno, enquanto as crianças canadenses tiveram uma introdução precoce de alimentos enriquecidos com ferro, sendo que aos 3 meses, apenas $13 \%$ delas estavam em aleitamento materno exclusivo.

CALVO e col. (1992), num estudo com crianças argentinas alimentadas exclusivamente com leite materno até os 6 meses, encontraram valores médios de hemoglobina de $11,1 \mathrm{~g} / \mathrm{dL}$ aos 3 meses e 11,2 g/dL aos 6 meses. Estes valores superaram os encontrados nas crianças do Centro de Lactação de Santos de 10,0 g/dL e 10,4 g/dL, respectivamente.

Geralmente aceita-se que a deficiência de ferro é rara entre as crianças nascidas a termo e alimentadas exclusivamente com leite materno durante os primeiros seis meses de vida. DEWEY e col. (1998) citam que esta afirmação deriva de estudos com populações afluentes, onde as médias de peso ao nascer e as reservas de ferro são relativamente altas. Trabalhos que apontam esses resultados são escassos nas populações de países em desenvolvimento. As crianças deste estudo apresentaram peso normal ao nascer e baixa concentração de hemoglobina. 
Todo o empenho deve ser feito para assegurar o sucesso do aleitamento materno exclusivo até pelo menos 4 meses, conforme recomendação da OMS (WHO 1991). A partir dessa idade, deve ser considerada a hipótese de que crianças alimentadas exclusivamente com leite materno, estejam com suas reservas de ferro esgotadas.

Neste estudo, $70,2 \%$ de crianças com 6 meses de idade apresentaram valores de hemoglobina inferiores a $11,0 \mathrm{~g} / \mathrm{dL}$ (Tabela 7 ), sendo esta a prevalência de anemia entre tais crianças, de acordo com a OMS (1975). É provável que a situação encontrada se repita com as outras crianças quando elas atingirem 6 meses.

As gestantes juntamente com as crianças fazem parte do grupo vulnerável no qual a anemia é apontada como importante problema de saúde pública. SANCHEZ-MEDAL (1969) afirma que as mulheres grávidas e as crianças até um ano encontram-se no período mais crítico, no que se refere à deficiência de ferro. Este autor chama atenção para a escassez de informaçōes relativas à influência que os níveis hematológicos maternos exercem sobre os da criança.

Do grupo de crianças cujo o sangue foi colhido na maternidade $(n=59)$ foi colhido também o da mãe. Observa-se na Tabela 9 que $71,2 \%$ das mães apresentaram niveis de hemoglobina abaixo de $11,0 \mathrm{~g} / \mathrm{dL}$, sendo portanto, consideradas anêmicas (OMS 1968). ARRUDA (1998) encontrou $69,1 \%$ de parturientes anêmicas em Pernambuco. Destaca-se que estas prevalências são bastante superiores àquelas referidas por SZARFARC (1972) e 
SINISTERRA-RODRIGUES (1989) que encontraram, respectivamente, $15,1 \%$ e $29,0 \%$ numa população de parturientes do município de São Paulo. Como a população de mães que procuram o Centro de Lactação é semelhante, é provável que as mães das demais crianças deste estudo apresentem a mesma prevalência.

Tabela 9 - Distribuição das gestantes, segundo a concentração de hemoglobina. Maternidade do Hospital Guilherme Álvaro. Municipio de Santos - SP, 1995/96.

\begin{tabular}{ccc}
\hline $\begin{array}{c}\text { Hemoglobina } \\
(\mathrm{g} / \mathrm{dL})\end{array}$ & $\mathrm{n}$ & Gestantes \\
$<11,0$ & 42 & $\%$ \\
$\geq 11,0$ & 17 & 71,2 \\
& 59 & 28,8 \\
\hline \hline Total & & 100,0 \\
\hline \hline $\bar{X}=10,05 \mathrm{~g} / \mathrm{dL}$ & \\
$\mathrm{DP}=1,43$ & &
\end{tabular}

Encontramos na literatura pesquisada, resultados controversos sobre o papel da deficiência de ferro materna, identificado pelo valor de hemoglobina, sobre o fornecimento de ferro ao feto. WOODRUFF e BRIDGEFORTH já afirmavam em 1953 que, a anemia da mãe não influenciava a hemoglobina, nem a concentração de ferro da criança.

Neste estudo não foi encontrada correlação entre o nível de hemoglobina da mãe e do recém-nascido (Coeficiente de Pearson $=0,22$ ). Resultado semelhante foi encontrado por MORTON e col. (1988) num estudo em 
Londres, com recém-nascidos de uma área da cidade com grande concentração de pessoas originárias de Bangladesh. No estudo de BRATLID e MOE (1980) com 54 crianças norueguesas, citado anteriormente, foi registrado uma correlação fraca, sendo que a mesma não foi significante.

Nos primeiros meses de vida, a demanda de ferro necessária ao crescimento é suprida pela reserva neonatal e a absorção do ferro dos alimentos tem um papel muito restrito. Quanto maior essa reserva, maior o crescimento que a criança suporta sem esgotá-la precocemente.

A taxa rápida de crescimento é considerada o principal fator no desenvolvimento da deficiência de ferro podendo afetar as reservas de ferro em crianças normais, como acontece nas crianças nascidas com baixo peso (LUNDSTRÖM e col. 1977).

A associação encontrada entre as concentrações de hemoglobina medida e estimada (Tabela 8) sugere que o crescimento adequado, como 0 encontrado neste estudo, exige uma quantidade de ferro maior do que aquela disponivel, ou seja, a expectativa verificada é de exaustão do ferro já no início do período. Essa associação mostra também que os valores baixos de concentração de hemoglobina não constituem um evento inesperado. Significa ainda que o crescimento, mesmo em velocidade adequada, conduz rapidamente à exaustão do ferro fetal. $O$ aumento observado na concentração de hemoglobina a partir dos 3 meses (Figura 5) é decorrente entre outros fatores, (COOK e col. 1996), do importante aumento da 
concentração de transferrina, proteina transportadora do ferro, que recicla este mineral existente de forma extremamente eficiente (Anexo 1 ). 0 leite materno tem a capacidade de aumentar a produção de transferrina justificando os muitos achados que mostram sua capacidade de proteger a criança contra a anemia ferropriva.

Deve ser considerado, também, que a quantidade de ferro do leite materno varia durante o periodo de amamentação. SIIMES e col. (1979), num estudo longitudinal sobre a concentração de ferro do leite materno, verificaram que os valores declinaram de $0,56 \mathrm{mg} / \mathrm{L}$ na segunda semana a $0,3 \mathrm{mg} / \mathrm{L}$ depois de 5 meses de lactação.

O COMMITTEE ON NUTRITION (1976) afirma que a deficiência de ferro continua a ser a causa mais comum de anemia na infância. Nas crianças menores de 1 ano nascidas a termo, o risco é aumentado quando as reservas neonatais se esgotam entre 4 e 6 meses. 0 mesmo comitê alerta que a necessidade de suplementação de ferro para crianças em aleitamento materno requer maiores investigações; no entanto, reconhece que ela deve começar a partir de 4 a 6 meses ou seja, quando as reservas de ferro estiverem esgotadas.

As crianças deste estudo apresentaram crescimento adequado, com baixo nível de concentração de hemoglobina durante o periodo estudado, decorrente provavelmente, do valor baixo de hemoglobina registrado ao nascer. Este resultado foi semelhante ao de CALVO e col. (1992). Estes

\footnotetext{
- Relatorio final enviado à FAPESP processo $n^{\circ} 94.4431$-3, 1997. Aleitamento materno, dieta de desmame e evoluçăo dos indicadores da situação orgânica de ferro.
} 
autores concluiram que, mesmo com a elevada biodisponibilidade de ferro do leite materno, ele é insuficiente para atender à demanda deste mineral, em uma criança com velocidade de crescimento adequado, a partir do $4^{\circ}$ mês de vida. Os autores afirmaram ainda que esses resultados reforçam a recomendação de que as crianças amamentadas devam receber ferro suplementar a partir do $4^{\circ}$ mês, quando as reservas deste mineral estarão provavelmente esgotadas. 


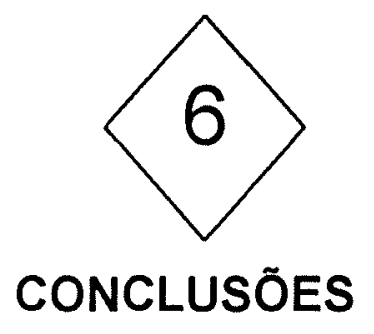




\section{CONCLUSÕES}

O estudo do crescimento e da concentração de hemoglobina de crianças do Centro de Lactação de Santos, alimentadas exclusivamente com leite materno nos primeiros 6 meses de vida, permitiu as seguintes conclusões:

- as crianças apresentaram crescimento adequado quando comparado com o padrão do NCHS e com os padrões construídos com valores de peso de crianças alimentadas com leite materno;

- a curva de hemoglobina das crianças apresentou a mesma tendência da curva do estudo de BRAULT-DUBUC e col., porém com valores mais baixos;

- $71,7 \%$ das crianças com 3 meses e $56,2 \%$ das crianças com 6 meses apresentaram nivel de concentração de hemoglobina abaixo de $10,5 \mathrm{~g} / \mathrm{dL}$, valor adotado como crítico para o diagnóstico de anemia. De acordo com o critério da OMS, 70,2\% das crianças com 6 meses de idade eram anêmicas (hemoglobina $<11,0 \mathrm{~g} / \mathrm{dL}$ );

- não foi observada correlação entre o crescimento das crianças durante o período estudado e os niveis de concentração de hemoglobina. 


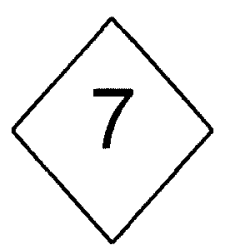

CONSIDERAÇÕES FINAIS 


\section{CONSIDERAÇÕES FINAIS}

Não existe qualquer dúvida a respeito da qualidade do leite materno como alimento único para o crescimento e desenvolvimento de crianças, ainda que elas apresentem velocidade de crescimento menor do que aquela observada em crianças com outros regimes alimentares. É fundamental a elaboração de curvas de crescimento construídas com dados antropométricos de crianças amamentadas exclusivamente ao seio. Estas curvas servirão como parâmetro adequado e tranquilizarão, tanto o pediatra quanto a mãe, em relação ao crescimento da criança.

É indispensável a supervisão do pessoal auxiliar que realiza e registra as medidas antropométricas, visando evitar a perda de dados indispensáveis ao estudo da evolução do crescimento infantil.

Com relação ao estado nutricional do ferro algumas dúvidas persistem: a variabilidade da concentração de hemoglobina ao nascimento, sugerindo concentrações orgânicas de ferro diferentes do esperado com a premissa do INACG (1979) de $75 \mathrm{mg} \mathrm{Fe/Kg} \mathrm{de} \mathrm{peso;} \mathrm{e} \mathrm{a} \mathrm{inexistência} \mathrm{de} \mathrm{uma} \mathrm{curva}$ de concentração de hemoglobina no primeiro semestre da vida, e mesmo no primeiro ano. Estas dúvidas se multiplicam com o achado de outros estudos. Por exemplo, HERNELL e LÖNNERDAL (1996), encontraram entre crianças de 6 meses, valores de concentração de hemoglobina semelhantes, independentemente da ingestão exclusiva de leite materno ou alimentos adicionados de ferro suplementar. É preocupante a verificação feita por WALTER (1993) de que as conseqüências da deficiência de ferro, no 
âmbito do desenvolvimento mental, permanecem mesmo após a eliminação da anemia, tendo em vista o grande número de crianças, deste estudo, com baixo nivel de concentração de hemoglobina aos 6 meses.

O problema da anemia nutricional se agrava quando as crianças amamentadas começam a ingerir outros alimentos. No levantamento realizado com os pediatras das Policlínicas de Santos, atendendo aos objetivos do projeto do qual este estudo faz parte (Aleitamento materno, dieta de desmame e evolução dos indicadores da situação orgânica de ferro), constatou-se que, nas dietas de desmame sugeridas pelos pediatras, os alimentos fontes de ferro não são privilegiados (Anexo 2).

A inexistência de opções de alimentos fontes de ferro que possam ser ingeridos pela criança em quantidade suficiente para atender à necessidade deste nutriente e a inexistência de alimentos fortificados à venda por preços similares ao do produto natural, fazem do suplemento profilático a estratégia mais viável, na prevenção da deficiência de ferro no primeiro ano de vida.

A observada não adesão ao suplemento de ferro, descrito por alguns autores (TORRES e col. 1994b, SZARFARC e col. 1996), pode ser vencida com novos produtos (por exemplo Ferro-Chelato) ou técnicas de consumo (uso do suplemento uma vez por semana).

É fundamental aprofundar o conhecimento sobre o nivel de concentração de hemoglobina de crianças em aleitamento materno e identificar valores críticos que protejam as crianças de danos causados pela anemia 
nutricional, evitando com isto a interrupção precoce do aleitamento materno exclusivo.

Destaca-se o significado positivo que teve para a população infantil do município de Santos, a criação de grupos de aleitamento materno exclusivo na maioria das Policlínicas de Saúde. 


\section{REFERÊNCIAS BIBLIOGRÁFICAS}

Ahn $\mathrm{CH}$, MacLean WC. Growth of the exclusively breast-fed infant. Am J Clin Nutr 1980; 33: 183-92.

Akré J. Infant feeding: the physiological basis, Bull World Health Organ 1989; Geneva, 67: 97p.

Andelman MB, Sered BR. Utilization of dietary iron by term infants. Am J Dis Child 1966; 111: 45-55.

Arruda IKG. Deficiência de ferro, de folato e anemia em gestantes atendidas no Instituto Materno Infantil de Pernambuco: Magnitude, fatores de risco e algumas implicações nos seus conceptos. Recife; 1998. [Tese de doutoramento - Departamento de Nutrição da Universidade Federal de Pernambuco].

Barros $F^{\circ}$ AA, Barbieri MA, Santoro JR. Influência da duração do aleitamento materno na morbidade de lactentes. Bol Oficina Sanit Panam 1985; 99: 594-604.

Barros FC, Victora CG, Vaughan JP. Breastfeeding and socieconomic status in Southern Brazil. Acta Paediatr Scand 1986; 75: 558-62.

Barros FC, Halpem R, Victora CG, Teixeira AMB, Béria JU. Promoção da amamentação em localidade urbana da região Sul do Brasil, estudo de intervenção randomizado. Rev Saúde Pública 1994; 28: 277-83.

Barros FC, Semer TC, Toniolli Filho S, Tomasi E, Victora CG. The impact of lactation centers on breastfeeding patterns, morbidity and growth, a birth cohort study. Acta Paediatr 1995; 84: 1221-6.

Biering-Sorensen F, Hilden J, Biering-Sorense $K$. Breast-feeding in Copenhagen, 1938-1977. Dan Med Bull 1980; 27: 42-8. 
Brady NC. The commitment to breast-feeding. Int J Gynecol Obstet 1990; 31 Suppl 1: 5-6.

Brandalise SR, Matsuda E. Anemias carenciais. In: Nóbrega $F$, editor. Desnutrição intra-uterina e pós natal. São Paulo: Panamed; 1981. p. 395405.

Bratlid D, Moe PJ. Hemoglobin and Serum ferritin levels in mothers and infants at birth. Eur J Pediatr 1980; 134: 125-7.

Brault-Dubuc M, Nadeau M, Dickie J. Iron status of French - Canadian children: a three year follow-up study. Hum Nutr Appl Nutr 1983; 37A: 21021.

Brown $\mathrm{KH}$, Blach RE, Romana $\mathrm{L}$, Kanashiro HC. Infant feeding pratices and their relationship with diarrheal and other diaseases in Huascar (Lima), Peru. Pediatrics $1989 ; 83: 31-40$.

Butte NF, Garza C, O'Brian Smith E, Nichols BL. Human milk intake and growth in exclusively breast-fed infants. J Pediatr 1984; 104: 187-95.

Calvo EB, Galindo AC, Aspres NB. Iron status in exclusively breast-fed infants. Pediatrics 1992; 90: 375-9.

Campos FCB, Henriques CMP, organizadores. Contra a maré a beira-mar: a experiência do SUS em Santos. $2^{\mathrm{a}}$ ed. São Paulo: Hucitec; 1997. 302 p.

Carvalhaes MABL. Crescimento nos primeiros dois anos de vida na área urbana do município de Botucatu, SP. São Paulo; 1988. [Dissertação de Mestrado-Faculdade de Saúde Pública da USP].

Castillo C, Atalah E, Riumalló J, Castro R. Breast-feeding and the nutritional status of nursing children in Chile. Bull Panam Health Organ 1996; 30: 12533. 
Center for Disease Control and Prevention, World Health Organization. Epi Info. Epidemiologia em microcomputadores: um sistema de processamento de texto, banco de dados e estatísticas [programa de computador]. Versão 5.01b. Atlanta: OPAS/WHO; 1990.

Chandra RK. Physical growth of exclusively breastfed infants. Nutr Res 1982; $2: 275-6$.

Chaves SP, Lei DLM, Lerner BR, Stefanini MLR. Aleitamento, estado nutricional e morbidade no primeiro ano de vida. Rev Nutr PUCCAMP 1995; 8: 31-46.

Cohen RJ, Brown KH, Canahuati J, Rivera LL, Dewey KG. Effects of age of introduction of complementary foods on infants breast milk intake, total energy intake, and growth: a randomised intervention study in Honduras. Lancet 1994; 343: 288-93.

Committee on Nutrition. Iron supplementation for infants. Pediatrics 1976; 58: $765-8$.

Cook JD, Skikne B, Baynes R. The use of the serum transferin receptor for the assessment of iron status. In: Leif Hallberg and Nils - Georg Asp editors. Iron nutrition in health and disease. London: John Libbey; 1996, p. 49-58.

Cunnigham AS. Morbidity in breast-fed and artificially fed infants. J Pediatr $1977 ; 90: 726$.

Dallman PR, Siimes MA, Stekel A. Iron deficiency in infancy and childhood. Am J Clin Nutr 1980; 33: 86-118.

Dallman PR, Reeves JD. Laboratory diagnosis of iron deficiency. In: Stekel A. Iron nutrition in infancy and childhood. New York: Nestlé, Vevey/Raven Press; 1984. p. 11-44. 
Dallman PR. Iron deficiency in the weanling: a nutritional problem on the way to resolution. Acta Paediatr Scand 1985; 323 Suppl: 59-67.

De Swiet M, Fayers $P$, Cooper L. Effect of feeding habit on weight in infancy. Lancet 1977; 1: 892-4.

DeMaeyer E, Adiels-Tegman M. The prevalence of anaemia in the world. World Health Stat Q 1985; 38: 302-16.

DeMaeyer E, Dallman P, Gurney JM, Hallberg L, Sood SK, Srikantia SG. Preventing and controlling iron deficiency anaemia through primary health care: a guide for health administrators and programme managers. Geneva: World Health Organization; 1989.

Dewey KG, Heining MJ, Nommsen LA, Peerson JM, Lönnerdal B. Growth of breast-fed and formula-fed infants from 0 to 18 months: The DARLING Study. Pediatrics 1992a; 89:1035-41.

Dewey KG, Peerson JM, Heing MJ, Nommsen LA, Lönnerdal B, Romanã GL et al. Growth patterns of breast-fed infants in affluent (United States) and poor (Peru) communities: implications for timing of complementary feeding. Am J Clin Nutr 1992b; 56: 1012-8.

Dewey KG, Cohen RJ, Rivera LL, Brown KH. Effects of age of introduction of complementary foods on iron status of breast-fed infants in Honduras. Am J Clin Nutr 1998; 67: 878-84.

Diaz S, Herreros C, Aravena R, Casado ME, Reyes MV, Schiappacasse V. Breast-feeding duration and growth of fully breast-fed infants in a poor urban chilean population. Am J Clin Nutr 1995; 62: 371-6.

Emond AM, Hawkins N, Pennock C, Golding J. Haemoglobin and ferritin concentrations in infants at 8 months of age. Arch Dis Child 1996; 74: 36-9. 
FAO/WHO. Energy and protein requirements. Geneva; 1973. (WHOTechnical Report Series, 522).

Feachem RG, Koblinsky MA. Interventions for the control of diarrhoeal diaseases among young children: promotion of breast-freding. Bull World Health Organ 1984; 62: 271-91.

Finch CA, Cook JD. Iron deficiency. Am J Clin Nutr 1984; 39: 471-7.

Ford K, Labbok M. Breast-feeding and child health in the United States. J Biosoc Sci 1993; 25: 187-94.

Fuchs SC, Victora CG, Martines J. Case-control study of risk of dehydrating diarrhoea in infants in vulnerable period after full weaning. BMJ 1996; 313 : $391-4$.

Giugliani ERJ, Victora CG. Normas alimentares para crianças brasileiras menores de dois anos: bases científicas. Brasilia: Organização Panamericana da Saúde; 1997. (OPAS/BRANOCD/006); 62p.

Grant JP. The state of the world's children. Oxford (UK): Oxford University Press; 1988.

Habicht J P, Martorell R, Yarbrough C, Malina RM, Klein RE. Height and weight standards for pre-school children. How relevant are ethnic differences in growth potential? Lancet 1974; i: 611-5.

Habicht JP, Da Vanzo J, Butz WP. Does breastfeeding really save lives, or are apparent benefits due to biases? Am J Epidemiol 1986; 123: 279-90.

Harisson GG. Application of incremental growth standars. Food Nutr Bull 1987; 6: 18-21. 
Hernell O, Lönnerdal B. Iron requeriments and prevalence of iron deficiency in term infants during the first 6 months of life. In: Leif Hallberg and Nils Georg Asp editors. Iron nutrition in health and disease. London: John Libbey; 1996. p. 129-36.

Hitchcock NE, Gracy M, Owles EN. Growth of healthy breast-fed infants in the first six months. Lancet $1981 ; 11: 64-5$.

[INACG] International Nutritional Anemia Consultative Group. Guidelines for irradication of iron deficiency. [Apresentado ao Meeting, Goteborg, Sweden, 1-4, June, 1977].

[INACG] International Nutritional Anemia Consultative Group. Iron deficiency in infancy and childhood. Washington (DC); 1979.

[INACG] International Nutrition Anemia Consultative Group. Measurements of iron status. Report. Washington (DC); 1985.

Jason JM, Nieburg P, Marks JS. Mortality and infections disease associated with infant feeding practices in developing countries. Pediatrics 1984; 74 Suppl: 702-27.

Jelliffe DB, Gurney M, Jellife EFP. Unsupplemented human milk and the nutrition of the exterogestate fetus. In: Proceedings of the 9th International Congress of Nutrition; 1972; Mexico. Basel: Karger; 1972. p. $77-85$.

Jelliffe DB, Jelliffe EFP. Human milk in the modern world. 2nd ed. Oxford (UK). Oxford University Press; 1978a.

Jelliffe DB, Jelliffe EFP. The volume and composition of human milk in poorly nourished communities: a review. Am J Clin Nutr 1978b; 31: 492-515.

Jelliffe DB, Jelliffe EFP. Adequacy of breastfeeding. Lancet 1979; ii: 691-2. 
Jolly RC. Breast-feeding and health care services. Int. J Gynecol Obstet 1990; 31 Suppl 1: 7-9.

Jorge João MF, Simas VA. Efeito do aleitamento materno sobre o estado nutricional do lactente. Hiléia Méd 1983; 4: 25-32.

Lerner BR. A alimentação e a anemia carencial em adolescentes. São Paulo; 1994. [Tese de Doutorado - Faculdade de Saúde Pública da USP].

Lozoff $B$, Júmenez E, Wolf AW. Long-term developmental outcome of infants with iron deficiency. N Engl J Med 1991; 325: 687-94.

Lundström MU, Siimes MA, Dallman PR. At what age does iron supplementation become necessary in low birth weight infants? J Pediatr 1977; 91: 878-81.

Marcondes E, Berquó E, Yunes J, Luongo J, Martins J de S, Zacchi MAS et al. Estudo antropométrico de crianças brasileiras de zero a doze anos de idade. São Paulo: Nestlé - Serviço de Informação Científica; 1971. (Anais Nestlé, 84).

Martines JC, Ashworth A, Kirkwood B. Breast-feeding among the urban poor southern Brazil: reasons fort termination in the first 6 months of life. Bull World Health Organ 1989; 67: 151-61.

Martinez GA, Nalezienski JP. The recent trend in breast-feeding. Pediatrics 1979; 64: 686-92.

McMillan JA, Landaw SA, Oski FA. Iron sufficiency in breast-fed infants and the availabity of iron from human milk. Pediatrics 1976; 58: 686-91.

Michaelsen KF, Milman N, Samuelson G. A longitudinal study of iron status in healthy Danish infants: effects of early iron status, growth velocity and dietary factors. Acta Paediatr 1995; 84: 1035-44. 
Mollison PL, Cutbush MA. Method of measuring a series of cases hemolytic disease of newborn Blood 1951; 6: 777-8.

Monteiro CA, Szarfarc SC. Estudo das condições de saúde das crianças do Município de São Paulo, SP (Brasil), 1984/1985. V. Anemia. Rev Saúde Pública 1987; 21: 255-60.

Monteiro CA, Zuniga HPP, Benicio MHA, Rea MF, Tudisco ES, Sigulem DM. The recent revival of breast-feeding in the city of São Paulo, Brazil. Am J Public Health 1987; 77: 964-6.

Monteiro CA, Rea MF. O aleitamento materno. In: Monteiro CA, organizador. Saúde e nutrição das crianças de São Paulo. São Paulo: HUCITEC/EDUSP; 1988. p. 55-77.

Monteiro CA, Zuniga HPP, Benicio MHA, Rea MF. Breast-feeding patterns and socioeconomic status in the city of São Paulo. J Trop Pediatr 1988; 34: 186-92.

Monteiro CA, Rea M, Victora CG. Can infant mortality be reduced by promoting breastfeeding? Evidence from São Paulo city. Health Policy Plan 1990; 5: 23-9.

Monzon MD. Anemia in infancy and childhood: a systematic approach to evaluation. Postgrad Med 1985; 78: 275-92.

Morton RE, Nysenbaum A, Price K. Iron status in the first year of life. J Pediatr Gastroenterol Nutr 1988; 7: 707-12.

Murahovschi J, Teruya KM, Nascimento ET, Bueno LGS, Pinheiro L, Maneta ME et al. Curvas e tabelas de crescimento de lactentes brasileiros de zero a seis meses de idade alimentados exclusivamente com leite materno. J Pediatr 1987; 63 (4): 1-25. 
[NCHS] National Center For Health Statistcs. Growth curves for children, birth - 18 years, United States. Vital Health Stat 1977; 11(165): 1-74.

Notzon F. Trends in infant feeding in developing countries. Pediatrics 1984; 74 Suppl: 648-66.

Onis M, Habicht JP. Anthropometric reference data for international use: recommendations from a World Health Organization Expert Committee. Am J Clin Nutr 1996; 64: 650-8.

[OMS] Organización Mundial de La Salud. Anemias nutricionales. Ginebra; 1968. (OMS - Serie de Informes Tecnicos, 405).

[OMS] Organización Mundial de la salud. Lucha contra la anemia nutricional, especialmente contra la carencia de hierro. Ginebra; 1975. (OMS - Serie de Informes Tecnicos, 580).

[OMS/UNICEF] Organização Mundial da Saúde/UNICEF. Reunião conjunta sobre alimentação de lactentes e crianças na primeira infância. Brasília: UNICEF; 1980.

[OMS] Organisation Mondiale de la Santé. Les modes actuels de l'allaitement maternel: rapport d'une étude collective sur l'allaitement maternel. Genève; 1981.

[OMS] Organización Mundial de la Salud. Medición del cambio del estado nutricional: directrices para evaluar el efecto nutricional de programas de alimentación suplementaria destinados a grupos vulnerables. Ginebra; 1983.

Oski FA. Iron supplementation and the breast-fed infant. J Pediatr Gastroenterol Nutr 1975; 4: 344-5.

Oski FA, Landaw SA. Inhibition of iron absorption from human milk by baby food. Am J Dis Child 1980; 134: 459-60. 
Oski FA, Naiman JL. Hematologia do recém-nascido. $3^{a}$ ed. São Paulo: Manole; 1984.

Plank SJ, Milanesi ML. Infant feeding and infant mortality in rural Chile. Bull World Health Organ 1973; 48: 203-10.

Popkin BM, Adair L, Akin JS, Black R, Briscoe J, Fielger W. Breast feeding and diarrheal morbidity. Pediatrics 1990; 86: 874-83.

Rea, M.F. The Brazilian National Breastfeeding Programme: a sucess story. Int J Gynecol Obstet 1990; 31 Suppl 1: 79-82.

Rea MF, Berquó, ES. Impact of Brazilian National Breast-feeding Programme on the mothers in Greater São Paulo. Bull World Health Organ 1990; 68: 365-71.

Roche AF, Himes JH. Incremental growth charts. Am J Clin Nutr 1980; 33: 2041-52.

Rowland MGM, Paul AA, Whitehead RG. Lactation and infant nutrition. Br Med Bull 1981; 37: 77-82.

Saarinen UM, Siimes MA, Dallman PR. Iron absorption in infants. High biovailability of breast milk iron as indicated by extrinsic tag method of iron absorption and by the concentration of serum ferritin. J Pediatr 1977; 91:369.

Saarinen UM. Need for iron supplementation in infants on prolonged breast feeding. J Pediatr 1978; 93: 177-80.

Saarinen UM, Siimes MA. Developmental changes in red blood cell counts and indices of infants after exclusion of iron deficiency by laboratory criteria and continuous iron supplementation. J Pediatr 1978; 92: 412-6. 
Saarinen UM, Siimes MA. Iron absorption from breast milk, cow's milk, and iron-suplemented formula: an opportunistic use of changes in total body iron determined by hemoglobin, ferritin, and body weight in 132 infants. Pediatr Res 1979; 13: 143-7.

Salmenparä L, Perheentupa J, Siimes MA. Exclusively breast-fed healthy infants grow slower than reference infants. Pediatric Res 1985; 19: 307-12.

Salzano AC, Torres MAA, Batista Filho M, Romani SAM. Anemias em crianças de dois serviços de saúde de Recife, PE (Brasil). Rev Saúde Pública 1985; 19: 499-507.

Sánchez Medal L. Iron deficiency in pregnancy and infancy. In: Abstracts of papers of the Symposium on Iron Metabolism and Anemia; 1969; Washington (DC). Washington (DC) PAHO; 1969. p. 9.

Scrimshaw NS, Taylor CE, Gordon JE. Interactions of nutrition and infection. Geneva: WHO; 1968. (World Health Organization Monograph Series, 57).

Seward JK, Serdula MK. Infant feeding and infant growth: task force on infant-feeding practices. Pediatrics 1984; 74 Suppl: 728-62.

Sichieri R. Anemia nutricional em crianças menores de 5 anos do município de São Paulo: papel da dieta na determinação de sua prevalência. São Paulo; 1987. [Tese de Doutorado - Faculdade de Saúde Pública da USP].

Sigulem DM, Tudisco ES, Goldemberg P, Athaide MMM, VAISMAN E. Anemia ferropriva no município de São Paulo. Rev Saúde Pública 1978; 12 : $168-78$.

Sigulem DM, Tudisco ES. Aleitamento natural em diferentes classes de renda no municipio de São Paulo. Arch Latinoam Nutr 1980; 30: 400-16. 
Siimes MA, Vuori E, Kuitunen P. Breast milk iron: a declining concentration during the course of lactation. Acta Paediatr Scand 1979; 68: 29-31.

Siimes MA, Salmenperä L, Perheentupa J. Exclusive breast-feeding for 9 months: risk of iron deficiency. J Pediatr 1984; 104: 196-9.

Sinisterra-Rodriguez OT. Estudo da influência da anemia e desnutrição materna sobre o peso ao nascer. São Paulo; 1989. [Dissertação de Mestrado - Faculdade de Saúde Pública da USP].

Souza SB. Tipo de aleitamento e morbidade. São Paulo; 1987. [Dissertação de Mestrado - Faculdade de Saúde Pública da USP].

Souza SB. Anemia e alimentação no primeiro ano de vida. São Paulo: 1994 [Tese de Doutoramento - Faculdade de Saúde Pública da USP].

Statistical Package for the Social Sciences: SPSS Base 7.0 for Windows. User's guide. Chicago, SPSS; 1996.

Stefanini MLR, Colli C, Lerner BR, Lei DLM, Chaves SP, DiPietro MS et al. Anemia e desnutrição em escolares da rede pública do município de Osasco. São Paulo, Brasil. Cad Saúde Pública 1995; 11: 439-47.

Stekel A. Prevención de la deficiencia de hierro. In: Resumo do IV Seminário Nestlé Nutrition - (El hierro en la alimentacion del lactante y del niño) 1982 nov 23 - 3 dez. Manila. NY: Raven Press NY; 1984a. p. 4953.

Stekel A. Necessidades de hierro en el lactante y el niño. In: Resumo do IV Seminário Nestlé Nutrition - (El hierro en la alimentacion del lactante y del niño) 1982 nov 23 - 3 dez. Manila. NY: Raven Press NY; 1984b. p.7-10.

Szarfarc SC. Anemia ferropriva entre parturientes e recém nascidos de uma população de baixo nível sócio econômico. São Paulo; 1972. [Tese de Doutorado - Faculdade de Saúde Pública da USP]. 
Szarfarc SC, Berg G, Santos ALS, Souza SB, Monteiro CA. Prevenção de anemia no primeiro ano de vida em centros de saúde do município de Santo André, São Paulo. J Pediatr 1996; 72: 329-34.

Taboada H. Rol del hierro en la nutrición infantil. Rev Chil Pediatr 1983; 54 : 47-57.

Torres MAA, Sato K, Queiroz SS. Anemia em crianças menores de dois anos atendidas nas unidades básicas de saúde no Estado de São Paulo, Brasil. Rev Saúde Pública 1994a; 28: 290-4.

Torres MAA, Sato K, Juliano Y, Queiroz SS. Terapêutica com doses profiláticas de sulfato ferroso como medida de intervenção no combate à carência de ferro em crianças atendidas em unidades básicas de saúde. Rev Saúde Pública 1994b; 28: 410-5.

Tricta Junior DF. Anemia fisiológica do lactente. J Pediatr 1986; 60: 105-10.

Underwood BA, Hofvander $Y$. Appropriate timing for complementary feeding of the breastfed infant: a review. Acta Paediatr Scand 1982; 294 Suppl: 132.

Vahlquist, B. The evolution of breast feeding in Europe. J Trop Pediatr $1975 ; 21: 11-8$.

Vannucchi $H$, Freitas MLS, Szarfarc SC. Prevalência de anemias nutricionais no Brasil. Cad Nutr 1992; 4: 7-26.

Venancio SI. A evolução da prática do aleitamento materno no Brasil nas décadas de 70 e 80 . São Paulo; 1996. [Dissertação de Mestrado Faculdade de Saúde Pública da USP].

Victora CG, Barros FC, Martines JC, Vaughan JP. Is prolonged breast feeding associated with malnutrition. Am J Clin Nutr 1984; 39: 307-14. 
Victora CG, Smith PG, Vaughan JP, Nobre LC, Lombardi C, Teixeira AMB et al. Evidence for protection by breast-feeding against infant deaths from infections diseases in Brazil. Lancet 1987; 2: 319-22.

Victora CG, Smith PG, Vaughan JP, Nobre LC, Lombardi C, Teixeira AMB et al. Infant feeding and death due to diarrhea: a case-control study. Am J Epidemiol 1989; 129: 1032-41.

Victora CG, Huttley SR, Fuchs SC, Nobre LC, Barros FC. Deaths due to dysentery, acute and persistent diarrhoea among Brazilan infants. Acta Paediatr 1992; 381 Suppl: 7-11.

Victora CG, Morris SS, Barros FC, Onis M, Yip R. The NCHS reference and the growth of breast-and bottle-fed infants. J Nutr 1998a; 128: 1134-8.

Victora CG, Morris SS, Barros FC, Horta BL, Weiderpass E, Tomasi E. Breast-feeding and growth in Brazilian infants. Am J Clin Nutr 1998b; 67: 452-8.

Walker, M. Um novo olhar sobre os riscos da alimentação infantil. J Hum Lact 1993; 9: 97-107.

Walter T, De Andraca I, Chadud P, Perales CG. Iron deficiency anemia: adverse effects on infant psychomotor development. Pediatr 1989; 84: 7-17.

Walter T. Impact of iron deficiency on infancy and childhood. Eur $\mathbf{J}$ Clin Nutr 1993; 47: 307-16.

Waterlow JC, Thomson AM. Observations on the adequacy of breastfeeding. Lancet $1979 ; 2: 238-42$.

Waterlow JC, Ashworth A, Griffiths M. Faltering infant growth in lessdeveloped countries. Lancet 1980; ii:1176-8. 
Waterlow JC. Malnutrición proteico-energética. Washington (DC): OPS/OMS; 1996. Lactancia Materna y destete; p. 319-55. (OPS Publicación Científica, 555).

White A, Handler $P$, Smith EL. Hemoproteinas e porfirinas. In: White A, Handler $P$, Smith EL, editores. Princípios de bioquímica. $5^{a}$ ed. Rio de Janeiro, Guanabara: Koogan; 1976. p. 139-50.

Whitehead RG, Paul AA. Growth standards for early infancy. Lancet 1981; 2: $419-20$.

Whitehead RG, Paul AA. Growth charts and the assessment of infant feeding pratices in the western world and in developing countries Early Hum Dev 1984; 9: 187-207.

[WHO] World Health Organization Working Group. Use and interpretation of anthropometric indicators of nutritional status. Bull World Health Organ 1986; 64: 929-41.

[WHO] World Health Organization. Innocenti Declaration on the protection, promotion and support of breast-feeding. Ecol Food Nutr 1991; 26: 271-3.

[WHO] World Health Organization. Working Group On Infant Growth. An evaluation of infant growth. Geneva; 1994. (WHO Doc/WHO/NUT/94.8).

[WHO] World Health Organization. Physical status: the use and interpretation of anthropometry: report of a WHO Expert Committee. Geneva;1995. (WHO - Techical Report Series, 854).

Winikoff B, Baer EC. The obstetrician's opportunity: translating "breast is best" from theory to practice. Am J Obstet Gynecol 1980; 138: 105-17.

Woodruff CW; Bridgeforth EB. Relationship between the haemogram of the infant and that of the mother during pregnancy. Paediatr 1953; 12: 681-6. 
Woodruff CW. Iron deficiency in infancy and childhood. In: Symposium on Nutrition in Pediatrics. Pediatr Clin North America 1977; 24: 85-94. 


\section{ANEXO I}

Distribuição da concentração de capacidade total de ligação de ferro(CTLF $\mu \mathrm{g} / \mathrm{dL})$, segundo idade

\begin{tabular}{|c|c|c|c|c|}
\hline $\begin{array}{c}\text { Idade } \\
\text { (meses) }\end{array}$ & N. $^{\circ}$ & Média & $\begin{array}{c}\text { desvio } \\
\text { padrão }\end{array}$ & Mediana \\
\hline 0 & 64 & 655 & 315 & 686 \\
1 & 44 & 1075 & 301 & 1121 \\
$2-4$ & 47 & 1016 & 229 & 1027 \\
$5-7$ & 68 & 1037 & 221 & 1057 \\
$8-13$ & 70 & 1086 & 269 & 1119 \\
& & & & \\
gestantes & 62 & 1019 & 280 & 1045 \\
\hline
\end{tabular}

Distribuição da saturação de transferrina (SAT\%), por idade

\begin{tabular}{|c|c|c|c|c|}
\hline $\begin{array}{c}\text { Idade } \\
\text { (meses) }\end{array}$ & N. $^{\circ}$ & Média & $\begin{array}{c}\text { desvio } \\
\text { padrão }\end{array}$ & Mediana \\
\hdashline 0 & 64 & 22.2 & 25.3 & 18.1 \\
1 & 44 & 18.3 & 13.4 & 15.8 \\
$2-4$ & 47 & 12.7 & 5.0 & 12.9 \\
$5-7$ & 68 & 12.0 & 4.0 & 11.8 \\
$8-13$ & 69 & 13.8 & 7.9 & 11.7 \\
& & & & \\
gestantes & 60 & 15.5 & 8.9 & 13.8 \\
\hline
\end{tabular}

Fonte: Dados do trabalho Aleitamento materno, dieta de desmame e evolução dos indicadores da situação orgânica de ferro. 


\section{ANEXO II}

Instrumento utilizado no trabalho, "Aleitamento materno, dieta de desmame e evolução dos indicadores da situação orgânica de ferro". 
Prezado Colega,

Dada a importância da alimentaçño para a qualidade de crescimento e desenvolvimento da criança especialmente no primeiro ano de vida e, considerando que os pediatras exercem um papel de inegável importância sobre a população, queremos saber como o colega orienta, na sua prática diária, a alimentação dos infantes.

Para tal, solicitamos que preencha o formulário anexo.

Certos de contar com a sua indispensável colaboração, colocamoncis à disposição para quaisquer esclarecimentos,

Atenciosamente,

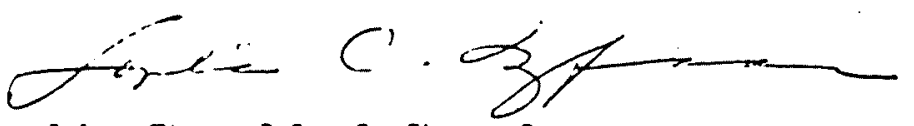

Sophia Cornbluth Szarfarc

Faculdade de Saúde Pública / USP

Av. Dr. Arnaldo 715 CEP - 01246-904 São Paulo/SP

Fone/Fax - 011 - 852-6748 e 3064-6068 


\section{ALIMENTAÇ.ÃO NO PRIMEIRO ANO DE VIDA}

\section{$A$ introdução de alimentos}

\section{1 - LEITE}

\begin{tabular}{|c|c|c|c|}
\hline $\begin{array}{c}\text { IDADE } \\
\text { nieses }\end{array}$ & $\begin{array}{c}\text { TPPO } \\
(*)\end{array}$ & MODO DE PREPARO (**) & $\begin{array}{c}\text { FREQ } \\
\text { diária }\end{array}$ \\
\hline & & & \\
\hline & & & \\
\hline & & & \\
\hline & & & \\
\hline & & & \\
\hline
\end{tabular}

(*) - 1 - leite fluido

2 - leite em pó integral

3 - leites formulados

4 - outro-especiticar

$\left.{ }^{* *}\right)$ - referir a diluição, uso de adoçantes, espessantesse etc.

\section{2-OVO}

\begin{tabular}{|c|c|c|c|}
\hline $\begin{array}{c}\text { DADE } \\
\text { meses }\end{array}$ & GEMAA & INTEIRO & $\begin{array}{c}\text { FREQ } \\
\text { semana }\end{array}$ \\
\hline & & & \\
\hline & & & \\
\hline & & & \\
\hline
\end{tabular}

\section{3 - FRUTAS}

\begin{tabular}{|l|l|l|l|l|}
\hline $\begin{array}{l}\text { DADE } \\
\text { meses }\end{array}$ & ESPEC.E & $\begin{array}{l}\text { PREPARO } \\
\left(\begin{array}{l}\text { QUANT. } \\
\text { menEQ. }\end{array}\right.\end{array}$ & $\begin{array}{l}\text { FRE } \\
\text { volume }\end{array}$ \\
\hline & & & & \\
\hline & & & & \\
\hline & & & & \\
\hline
\end{tabular}

$\left(^{*}\right)-1$ - suco só de frutas

4 - suco com água

2 - suco com leite

5 - papa de frutas

3 - suco com cereais

\section{4 - PAPA SALGADA}




\begin{tabular}{|l|l|l|}
\hline $\begin{array}{l}\text { DADE } \\
\text { meses }\end{array}$ & PREPARO $\left.{ }^{*}\right)$ & $\begin{array}{l}\text { FREQ } \\
\text { diaria }\end{array}$ \\
\hline & & \\
\hline & & \\
\hline & & \\
\hline & & \\
\hline & & \\
\hline
\end{tabular}

(*) - Descreva sucintamente os ingredientes que sāo recomendado assim como a técnica de preparo

\section{5 - ISO DE ALIMENTOS NNDUSTRIALIZADOS}

Com exceção do leite

a - Sua clientela costuma utiliza-los?

SIM

$\mathrm{NĂO}$

b - A mãe recebe orientação sua para a seleção desses alimentos?

SIM NÃO

c-De acordo com a sua experiência, a criança aceita melhor:

alimentos caseiros

alimentos industrializados

é indiferente

não tem a informação 


\section{6 - NECESSIDADES NUTRICIONAIS}

Assinale, na lista abaixo, as opcões que, na sua opinião, justificam a introdução das preparações referidas

\begin{tabular}{|l|l|l|l|l|}
\hline FUNCAO & LEITE & OVO & FRUTAS & PAPA \\
\hline variedade na alimentaçio & & & & \\
\hline satisfazer a uma necessidade social & & & & \\
\hline fornecer enengia (calorias) & & & & \\
\hline fornecer hidratos de cartiono & & & & \\
\hline fornecer fibras & & & & \\
\hline fornecer gorduras & & & & \\
\hline fornecer proteinas & & & & \\
\hline fornecer vitaminas em geral & & & & \\
\hline fornecer vitamina A & & & & \\
\hline fornecer vitamina C & & & & \\
\hline foruccer minerais em gernl & & & & \\
\hline formecer calcio & & & & \\
\hline fornecer ferro & & & & \\
\hline fornecer hgua & & & & \\
\hline regularizar o funcionamento intestinal & & & & \\
\hline outros (especificar) & & & & \\
\hline & & & & \\
\hline & & & & \\
\hline
\end{tabular}

\section{7 - INFORMA ÇOES ADICIONAIS}

No seu dia a dia, seus clientes são orientados para ingerir os alimentos utilizando:

\begin{tabular}{|l|l|l|}
\hline & SIM & NÃO \\
\hline MAMADEIRA & & \\
\hline CHUCA & & \\
\hline COLHER & & \\
\hline CANECO & & \\
\hline OUTRO (ESPECIFICAR) & & \\
\hline
\end{tabular}

